\title{
Roles of the N-terminal domain and remote substrate binding subsites in activity of the debranching barley limit dextrinase
}

\author{
Andersen, Susan; Svensson, Birte; Møller, Marie Sofie
}

Published in:

Biochimica et Biophysica Acta - Proteins and Proteomics

Link to article, DOI:

10.1016/j.bbapap.2019.140294

Publication date:

2020

Document Version

Peer reviewed version

Link back to DTU Orbit

Citation (APA):

Andersen, S., Svensson, B., \& Møller, M. S. (2020). Roles of the N-terminal domain and remote substrate binding subsites in activity of the debranching barley limit dextrinase. Biochimica et Biophysica Acta - Proteins and Proteomics, 1868(1), [140294]. https://doi.org/10.1016/j.bbapap.2019.140294

\section{General rights}

Copyright and moral rights for the publications made accessible in the public portal are retained by the authors and/or other copyright owners and it is a condition of accessing publications that users recognise and abide by the legal requirements associated with these rights.

- Users may download and print one copy of any publication from the public portal for the purpose of private study or research.

- You may not further distribute the material or use it for any profit-making activity or commercial gain

- You may freely distribute the URL identifying the publication in the public portal 


\section{Journal Pre-proof}

Roles of the N-terminal domain and remote substrate binding subsites in activity of the debranching barley limit dextrinase

Susan Andersen, Birte Svensson, Marie Sofie Møller

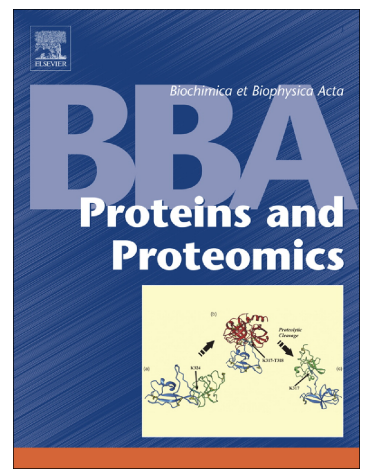

PII:

$$
\text { S1570-9639(19)30180-3 }
$$

DOI: https://doi.org/10.1016/j.bbapap.2019.140294

Reference:

$$
\text { BBAPAP } 140294
$$

To appear in:

$$
\text { BBA - Proteins and Proteomics }
$$

Received date:

16 July 2019

Revised date: 15 September 2019

Accepted date:

10 October 2019

Please cite this article as: S. Andersen, B. Svensson and M.S. Møller, Roles of the Nterminal domain and remote substrate binding subsites in activity of the debranching barley limit dextrinase, BBA - Proteins and Proteomics(2019), https://doi.org/10.1016/ j.bbapap.2019.140294

This is a PDF file of an article that has undergone enhancements after acceptance, such as the addition of a cover page and metadata, and formatting for readability, but it is not yet the definitive version of record. This version will undergo additional copyediting, typesetting and review before it is published in its final form, but we are providing this version to give early visibility of the article. Please note that, during the production process, errors may be discovered which could affect the content, and all legal disclaimers that apply to the journal pertain.

(C) 2019 Published by Elsevier. 


\section{Title page}

Roles of the N-terminal domain and remote substrate binding subsites in activity of the debranching barley limit dextrinase

Susan Andersen, Birte Svensson, Marie Sofie Møller*

Enzyme and Protein Chemistry, Department of Biotechnology and Biomedicine, Technical University of Denmark, Søltofts Plads, building 224, DK 2800 Kgs. Lyngby, Denmark

*Corresponding author: Marie Sofie Møller. E-mail: msmo@dtu.dk; Tel. +45 45252741 


\begin{abstract}
Barley limit dextrinase $(H v \mathrm{LD})$ of glycoside hydrolase family 13 is the sole enzyme hydrolysing $\alpha-1,6-$ glucosidic linkages from starch in the germinating seed. Surprisingly, $H v L D$ shows 150- and 7-fold higher activity towards pullulan and $\beta$-limit dextrin, respectively, than amylopectin. This is investigated by mutational analysis of residues in the N-terminal CBM-21like domain (Ser14Arg, His108Arg, Ser14Arg/His108Arg) and at the outer subsites +2 (Phe553Gly) and +3 (Phe620Ala, Asp621Ala, Phe620Ala/Asp621Ala) of the active site. The Ser14 and His108 mutants mimic natural LD variants from sorghum and rice with elevated enzymatic activity. Although situated about $40 \AA$ from the active site, the single mutants had $15-40 \%$ catalytic efficiency compared to wild type for the three polysaccharides and the double mutant retained $27 \%$ activity for $\beta$-limit dextrin and $64 \%$ for pullulan and amylopectin. These three mutants hydrolysed 4,6-O-benzylidene-4-nitrophenyl- $6^{3}-\alpha$-D-malto triosyl-maltotriose (BPNPG3G3) with $51-109 \%$ of wild-type activity. The results highlight that the $\mathrm{N}$-terminal CBM21-like domain plays a role in activity. Phe553 and the highly conserved Trp512 sandwich a substrate main chain glucosyl residue at subsite +2 of the active site, while substrate contacts of Phe620 and Asp621 at subsite +3 are less prominent. Phe553Gly showed $47 \%$ and $25 \%$ activity on pullulan and BPNPG3G3, respectively having a main role at subsite +2 . By contrast at subsite +3 , Asp621Ala increased activity on pullulan by 2.4 -fold, while Phe620Ala/Asp621Ala retained only $7 \%$ activity on pullulan albeit showed $25 \%$ activity towards BPNPG3G3. This outcome supports that the outer substrate binding area harbour preference determinants for the branched substrates amylopectin and $\beta$-limit dextrin.
\end{abstract}

\title{
Key words
}

Glycoside hydrolase family 13 subfamily 13; carbohydrate binding module 21-like; pullulanase; amylopectin; $\beta$-limit dextrin; $\alpha$-limit dextrin

\section{Abbreviations}

BPNPG3G3, 4,6- $O$-benzylidene-4-nitrophenyl- $6^{3}-\alpha$-D-maltotriosyl-maltotriose; CBM, carbohydrate binding module; $\mathrm{CD}$, cyclodextrin; $\mathrm{GG}^{2} 3 \mathrm{G}^{2} 3,6^{3}-\alpha$-D-glucosyl-maltotriosylmaltotriose; $\mathrm{G}_{2} \mathrm{SG}^{2} 4,6^{3}$ - $\alpha$-D-maltosyl-6-thiomaltotetraose; GH13, glycoside hydrolase family 13; GH13_13, GH13 subfamily 13; HvLD, Hordeum vulgare limit dextrinase; LD, limit dextrinase; OsLD, Oryza sativa subsp. indica 93-11 (rice) limit dextrinase; PDB, Protein Data Bank; PUL, pullulanase; PULI, type I pullulanase; PULII; type II pullulanase; SbLD, Sorghum bicolor (L.) Moench limit dextrinase; SbLD-GD, Sorghum bicolor frequent allele limit dextrinase; SbLD-RA, Sorghum bicolor rare allele limit dextrinase; SBS, surface binding site; SPR, surface plasmon resonance. 


\section{Introduction}

Starch is the major seed storage polysaccharide in cereal crops (rice, maize, wheat, barley, and sorghum) and the most abundant $\alpha$-glucan in human diet [1]. Notably, starch holds great potential in carbohydrate-based foods with beneficial qualities in human nutrition as resistant starch or prebiotics [2] as well as in feed-stocks for bioethanol production [3]. Starch is deposited as semi-crystalline supramolecular structures referred to as granules composed of two polysaccharides, amylose and amylopectin, of a typical weight ratio of 1:3. While amylose is an almost linear $\alpha$-1,4-glucan, amylopectin carries $\alpha$-1,6-branch chains at about $5 \%$ of the glucosyl residues. The degree of polymerisation, branch chain-length distribution, and branching pattern in amylopectin are plant-specific [4].

Despite the simplicity of the chemical structure of the $\alpha$-glucan substrates of glycoside hydrolase family 13 (GH13) more than 20 enzyme specificities catalyse their conversions as reflected also in the division of GH13 into 42 subfamilies [5-7] (Carbohydrate-Active enZymes database, CAZy; http://www.cazy.org/; [5]). Among GH13 members, $\alpha$-glucan debranching enzymes cover a surprising variety of substrate specificities characterised by specific protein structural elements and sequence motifs [8]. Limit dextrinase from barley (Hordeum vulgare) (HvLD) belongs to the type I pullulanases (PULI) (EC 3.2.1.41), which exclusively act on $\alpha$-1,6-glucosidic linkages, in contrast to the type II pullulanases (PULII) hydrolysing both $\alpha-1,4-$ and $\alpha-1,6$-glucosidic linkages [8]. $H \nu \mathrm{LD}$ is categorized into GH13 subfamily 13 (GH13_13) [5,8] containing $H v$ LD-like debranching enzymes and closely related bacterial pullulanases (PULs). $H v$ LD-like enzymes are commonly referred to as plant PULs due to their high activity towards pullulan $[9,10]$, a water-soluble linear polysaccharide composed of $\alpha-1,6$-connected maltotriose repeats from the yeast-like Aureobasidum pullulans [11]. Thus pullulan is not a natural substrate of plant PULs. These enzymes are therefore named limit dextrinases (LDs) after their natural substrates limit dextrins formed in the starch catabolism during germination.

$H \nu \mathrm{LD}$ is the sole debranching enzyme in germinating barley seeds and acts on $\alpha-1,6-$ linkages in $\alpha$-glucans, primarily $\alpha$ - and $\beta$-limit dextrins released from storage starch by concerted action of the amylolytic enzymes; $\alpha$-amylase, $\beta$-amylase, and $\alpha$-glucosidase $[12$ 16]. $H v \mathrm{LD}$ has high activity on pullulan, as opposed to the other debranching enzyme in plants isoamylase of GH13_11, that is confined to diurnal starch metabolism [17]. Surprisingly, $H v \mathrm{LD}$ has about two orders of magnitude lower activity for amylopectin than pullulan $[18,19]$. $H v \mathrm{LD}$ possesses the typical core multi-modular architecture of GH13 of a catalytic $(\beta / \alpha)_{8}$-barrel fold with an intimately associated $\mathrm{C}$-terminal antiparallel $\beta$-sandwich domain $[21,24,25]$. In addition it contains an N-terminal family 21-like carbohydrate binding module (CBM21-like) found in PULIs [20,21] followed by a CBM48 (Fig. 1). No carbohydrate binding function has yet been demonstrated for CBM48 from PULIs or the CBM21-like N-terminal domain although these both are starch binding domain CBM families [22,23].

The HvLD CBM21-like domain structurally resembles the CBM21 of Rhizopus oryzae glucoamylase [26], but residues from the two binding sites in this glucoamylase starch binding domain are not conserved in $H v \mathrm{LD}$ [21]. Indeed for other debranching enzymes, which have an N-terminal CBM41, CBM48, and/or CBM68 starch binding domains, confirmed ligand binding is rare, albeit seen to CBM41 of Streptococcus pneumonia PULI from GH13_12 [27] and Klebsiella pneumoniae PULI [28], and CBM68 in Anoxybacillus sp. LM 18-11 PUL of GH13_14 [29]. The consequence of these remote binding sites for enzyme function is not understood. It is tempting to categorise these sites as surface binding sites (SBS), which are situated outside of the active site region and commonly contribute to function of GH13 enzymes [30-32]. In LDs a possible involvement of the CBM21-like 
domain in activity was highlighted as evidenced by sorghum (Sorghum bicolor (L.) Moench) and rice (Oryza sativa subsp. indica 93-11) GH13_13 LDs. Firstly, a low-frequency allele of the drought-tolerant cereal sorghum was associated with the starch metabolic gene encoding $\mathrm{LD}(S b \mathrm{LD})$ and a homozygote of this sorghum line compared to the line carrying the frequent allele conferred $67 \%$ higher activity towards pullulan and $41 \%$ higher in vitro digestibility of starch [33]. These effects were suggested to stem from glycine and aspartic acid in

Fig. 1. Overall structure of $H v \mathrm{LD}$ (PDB ID: 4AIO) with $6^{3}-\alpha$-D-glucosyl-maltotriosyl-maltotriose $\left(\mathrm{GG}^{2} 3 \mathrm{G}^{2} 3\right.$; purple sticks; form PDB ID: 4J3X) and a branched oligosaccharide (G3G 3 ; green sticks; from PDB ID: 4J3W) in the active site. The CBM21-like N-terminal domain is in red; CBM48 in teal; the catalytic domain in grey; and the C-terminal domain in orange. Ser14, Ala90 and His 108 in the N-terminal domain are shown as green spheres; catalytic residues Asp473, Gln510, Asp642 as yellow spheres; the Asp600-Leu622 loop in pink; Phe620 and Asp621 as violet-purple spheres; Trp512 and Phe553 as deep blue spheres.

the N-terminal domain of the frequent allele LD, referred to as $S b \mathrm{LD}-\mathrm{GD}$, being mutated to arginine and alanine in the rare allele, $S b$ LD-RA. These positions correspond to Ser14 and Ala90 in the HvLD CBM21-like domain [33]. Secondly, examination of enzyme activities in developing rice seeds using zymography revealed two polymorphic LD (OsLD) variants which differ at nine amino acid positions, of which one aligns with His 108 in the $H v L D$ CBM21-like domain [34].

Specificity of GH13 enzymes beyond direct protein residue-substrate contacts is defined by the topology of the active site, which in debranching enzymes has two characteristic parallel crevices [35]. Also short canonical regions extending from $\beta$-strands of the catalytic $(\beta / \alpha)_{8^{-}}$ barrel display conserved sequence motifs correlated with different substrate specificities [6]. $H v$ LD Trp512 belongs to conserved region III associated with the fifth $\beta$-strand of GH13 [6] and forms an aromatic sandwich with Phe553, situated in a short loop between the sixth $\beta$ strand and sixth $\alpha$-helix of the catalytic $(\beta / \alpha)_{8}$-barrel. This structural element flanks the substrate main chain at subsite +2 [19] (Fig. 2A and 2B) and is generally critical for substrate binding [36]. In different $H v L D$ complexes Trp512 stacks onto specific glucosyl residues of cyclodextrins (CDs) and $\alpha$-limit dextrins, i.e. maltooligosaccharides containing one or more $\alpha-1,6$-linkages $[19,24]$. Phe553 in the three-dimensional space superimposes with tyrosine or phenylalanine in GH13_12-14 members but adopts different conformations to optimize substrate interactions [19]. Its tight substrate sandwich with Trp512 is understood to control substrate positioning to assure productive accommodation of only $\alpha-1,6-$ and not $\alpha-1,4-$ linkages for hydrolysis between subsites +1 and -1 (Fig. 2A) [19]. $H v L D$ has high affinity for $\mathrm{CD}$ inhibitors $\left(K_{\mathrm{d}}\right.$ for $\beta$-CD is $0.7 \mu \mathrm{M}$ ) [24]. In crystal structures (PDB ID: $2 \mathrm{Y} 4 \mathrm{~S}, 2 \mathrm{Y} 5 \mathrm{E}$, and 4J3U) Phe553 intrudes into the central cavity of the CD ring interacting with subsites 0 ', +1 , +2 and +3 [19,24] (Fig. 2C). Recently, an important role of the corresponding Phe746 of $K$. pneumoniae PULI has been shown in inhibition by $\beta-\mathrm{CD}$, as a 1,700 -fold increase of

Fig. 2. Nomenclature and overview of subsites in the $H v \mathrm{LD}$ active site. (A) $H v \mathrm{LD}$ (PDB ID: 4AIO) superimposed with $6^{3}-\alpha$-D-glucosyl-maltotriosyl-maltotriose $\left(\mathrm{GG}^{2} 3 \mathrm{G}^{2} 3\right.$; purple sticks; from PDB ID: 4J3X) and G3G 3 (green sticks; from PDB ID: 4J3W) in the active site. Catalytic site, yellow; Asp600-Leu622 loop, pink; Phe620 and Asp621, violetpurple; Trp512 and Phe553, deep blue; CBM21-like N-terminal domain, red; CBM48, teal; C-terminal domain, orange. The scissile $\alpha-1,6$ bond of the substrate is placed between subsites -1 and +1 and marked with an arrow. (B) $90^{\circ}$ right turned view of (A). (C) the same as (A), but with a $\beta$-CD inhibitor (cyan sticks; from PDB ID: 2Y4S) included. (D) schematic representation of the subsites accommodating $\mathrm{G}_{3} \mathrm{G}^{1} 3$ and $\mathrm{GG}^{2} 3 \mathrm{G}^{2} 3$. The grey hexagon indicates the reducing end of the oligos accharide. $K_{\mathrm{i}}$ for the Phe746Ala mutant and notably a reduction of both $K_{\mathrm{m}}$ and $k_{\text {cat }}$ were seen [28].

GH13_13 enzymes possess a characteristic long loop (Asp600-Leu622 in HvLD) as part of the connection between the sixth $\alpha$-helix and the seventh $\beta$-strand of the catalytic 
$(\beta / \alpha)_{8}$-barrel. This loop is lacking in the two other PULI subfamilies GH13_12 and GH13_14 [19] both harbouring PULs with higher activity on amylopectin than members of GH13_13 [8]. Structural evaluation of Phe620 and Asp621 on this long loop suggests they reach into the substrate binding area and narrow the main chain binding crevace beyond subsite +3 , thus restricting substrate main chain binding towards the reducing end to three glucosyl residues from the branch point [19] (Fig. 2). This long loop also moved towards the ring of maltosylS- $\beta$-cyclodextrin (G2S $\beta$-CD) and Phe620 stacks onto one of its glucose residues at subsite +3 [19]. However, in earlier solved $\alpha$-and $\beta$-CD complex structures this loop appeared dynamic based on absence of electron density for the side chain of Phe620 and of hydrogen bonds between Asp621 and the CDs [24]. The present work investigates the outer substrate aglycon binding region. Previously, an $H v \mathrm{LD}$ mutant Met440Gly addressed substrate branch chain binding beyond subsites $-3 /-4$, but was without effect on pullulan and resulted in 2.6-fold decrease in activity for amylopectin [19].

Here two aspects of polysaccharide binding and specificity of $H v \mathrm{LD}$ are explored. First, effects are analysed of Ser14Arg, His108Arg, Ser14Arg/His108Arg mutations in the Nterminal CBM21-like domain as guided by variants of sorghum and rice LDs. Secondly, based on comparison of crystal structures of oligosaccharide complexes of different debranching enzymes, active site mutants Phe553Gly, Phe620Ala, Asp621Ala, and Phe620Ala/Asp621Ala at the outer reducing-end main chain binding area probe specificity determinants in PULs.

\section{Materials and methods}

\subsection{Bioinformatic analysis}

Sequence comparison and structural modelling tools were applied to investigate the function of the N-terminal CBM21-like domain (residues 2-124) of $H v L D$. Protein sequence searching by BLASTP 2.7.1+ [37], after removal of fragment and redundant sequences (>99\% identity), resulted in 42 sequences (Table S1) subjected to multiple alignment performed in MAFFT [38] and visualised by ESPript using default settings (http://espript.ibcp.fr; [39]). The 42 sequences were moreover investigated through the Conserved Domains Database [40], the CAZy database (CAZy; http//www.cazy.org/; [5]), and dbCAN [41]. Structural positions of selected residues in $\mathrm{N}$-terminal domain of $\mathrm{HvLD}$ were compared with two homology models of $S b$ LD-RA (ABK63626.1; sequence only covering the $\mathrm{N}$-terminal domain) and OsLD (EEC76742.1). For both enzymes one model was made using HHpred [42] in combination with Modeller [43] with $H v L D$ in complex with the branched thio-linked hexasaccharide $6^{3}-\alpha$-D-maltosyl-6-thiomaltotetraose $\left(\mathrm{G}_{2} \mathrm{SG}^{2} 4\right)$ (PDB ID: $4 \mathrm{~J} 3 \mathrm{~V}$ ) as template and the second model by using SWISS-MODEL [44] and as template $H v \mathrm{LD}$ in complex with an amylopectin fragment $\mathrm{G}^{3} \mathrm{G}^{1} 3$ (PDB ID: $4 \mathrm{~J} 3 \mathrm{~W}$ ). The quality of the obtained models was evaluated by ProQ [45] and PyMol 2.0 (Schrödinger, LLC, New York, NY, USA) (Table S2). Two structure-based alignment tools FATCAT [46] and DALI against all PDB entries [47] were applied to investigate if the best match to the $\mathrm{N}$-terminal domain is still CBM21. Additionally, a structure-based sequence alignment of $H v L D$ and structuredetermined GH13_12-14 together with GH13_11 members (isoamylases and glycogen debranching enzymes) and sequences of characterised members of GH13_39 (PULs with dual $\alpha-1,4$ and $\alpha-1,6$-hydrolytic activity) was conducted by PROMALS3D [48] (Table S3).

\subsection{Mutagenesis and Pichia pastoris transformation}

Established methods for expression, mutagenesis, screening and purification of $H v L D$ [18] were optimized to increase production efficiency and introduce His-Tag purification. Briefly, the $H v L D$ gene was codon optimised for expression in P. pastoris (Life Technologies, Carlsbad, USA) and cloned into the pPICZ $\alpha$ A vector (Invitrogen) for easy selection on zeocine and encoding an C-terminal His-tag. This was particularly important as 
$H \nu \mathrm{LD}$ mutated at subsites +2 and +3 was expected not to bind to $\beta$-CD-Sepharose used before for $H v \mathrm{LD}$ affinity chromatographic purification [18]. The Q5® Site-Directed Mutagenesis Kit (New England Biolabs Ltd., Ipswich, USA) was used for higher yield and fidelity of variant plasmids. Production and transformation of competent P.pastoris strain X33 cells was achieved using the Pichia EasyComp ${ }^{\mathrm{TM}}$ Kit (Invitrogen, Carlsbad, USA).

Overall screening and production time of recombinant $H v \mathrm{LD}$ variants was reduced by $50 \%$. Yields were typically $0.5 \mathrm{mg} \mathrm{L}^{-1}$ culture or less for mutants.

$H v$ LD mutants Ser14Arg, His108Arg, Ser14Arg/His108Arg, Phe553Gly, Phe620Ala and Phe620Ala/Asp621Ala were obtained (Q5® Site-Directed Mutagenesis Kit; New England Biolabs Ltd.) using $10 \mathrm{ng}$ pPICZ $\alpha \mathrm{A}-H \nu \mathrm{LD}$ double stranded (ds) DNA template. For Phe620Ala/Asp620Ala and Ser14Arg/His108Arg dsDNA templates were pPICZaA-HvLDPhe620Ala and pPICZ $\alpha \mathrm{A}-H \nu \mathrm{LD}-$ Ser14Arg, respectively. Mutagenic primers are given in Table S4. The site directed mutagenesis PCR protocol included an initial denaturation $(30 \mathrm{~s}$, $98^{\circ} \mathrm{C}$ ), followed by 25 cycles (each $10 \mathrm{~s}$ at $98^{\circ} \mathrm{C}, 30 \mathrm{~s}$ at a primer specific annealing temperature (Table S4), and $95 \mathrm{~s}$ at $72^{\circ} \mathrm{C}$ ) and a final extension $\left(2 \mathrm{~min}, 72^{\circ} \mathrm{C}\right)$. pPICZ $\alpha \mathrm{A}$ $H v \mathrm{LD}$ wild type and variants were transformed into E. coli $\mathrm{DH} 5 \alpha$ [49] using heat shock [50] and selected with $25 \mu \mathrm{g} \mathrm{mL}^{-1}$ zeocin (Invitrogen). Mutant plasmids were verified by sequencing (GATC Biotech, Konstanz, GER), linearized by PmeI (20 units; New England Biolabs), purified (GeneJet PCR Purification Kit; Fermentas, Waltham, USA), and precipitated (Pellet Paint ${ }^{\circledR}$ Co-Precipitant; Merck Millipore, Billerica, USA) yielding about 3 $\mu \mathrm{g}$ linearized plasmid. Electrocompetent $P$. pastoris X-33 cells were transformed using Pichia EasyComp ${ }^{\mathrm{TM}}$ Kit (Invitrogen) according to the manufacturer's recommendations, plated on yeast extract peptone dextrose with sorbitol (YPDS) supplemented with $100 \mu \mathrm{g} \mathrm{mL}$ ${ }^{1}$ zeocin (Invitrogen) and incubated at $30^{\circ} \mathrm{C}$ until colonies were visible. $H v L D$ production by $P$. pastoris transformants was assessed for small scale cultures $(10 \mathrm{~mL}$ buffered glycerolcomplex medium, BMGY; $\left.30^{\circ} \mathrm{C}, 24 \mathrm{~h}\right)$; cells were harvested $\left(3,000 \mathrm{~g}, 10 \mathrm{~min}, 22^{\circ} \mathrm{C}\right)$ and resuspended to a final $\mathrm{OD}_{600}=1$ in $\mathrm{BMGY}$ buffered methanol-complex medium (BMMY) $\left(22^{\circ} \mathrm{C}\right.$, methanol supplemented to $0.5 \%(\mathrm{v} / \mathrm{v})$ every $\left.24 \mathrm{~h}\right)$ with induction maintained for $72 \mathrm{~h}$. Supernatants were 10-fold concentrated (3000 g, Centricon, $30 \mathrm{kDa}$ cut-off; Millipore) prior to assaying activity (Limit-Dextrizyme tablets; Megazyme, Irishtown, IRL) essentially as previously described, but using $50 \mathrm{mM}$ instead of $100 \mathrm{mM}$ sodium acetate $\mathrm{pH} 5.5$ [18,51]. In addition, immunoblotting was done to confirm the presence of $H v \mathrm{LD}$ as described $[18,52]$. Based on the activity assay and immunoblot results well-expressing transformants were selected for protein production.

\subsection{Production and purification of recombinant $H v L D$}

$H v \mathrm{LD}$ wild type and variants were produced by high cell-density fermentation according to the Pichia Fermentation Process Guidelines in 2 L Fermentation Basal Salts Medium (Invitrogen) with a glycerol batch phase, a glycerol fed-batch phase, and a methanol fed-batch maintained for approximately $90 \mathrm{~h} \mathrm{[18]} \mathrm{using} \mathrm{a} 5 \mathrm{~L}$ bioreactor (Biostat B; B. Braun Biotech International, Melsungen, Germany). Cultures were centrifuged (8,000 g, $30 \mathrm{~min}$, $\left.4^{\circ} \mathrm{C}\right)$. The supernatants were filtered $(0.45 \mu \mathrm{m}$ Durapore membrane filters; Millipore), concentrated 10-fold (10-kDa cut-off filter, Pellicon ultra-filtration unit; Millipore), adjusted to $\mathrm{pH} 7.4$ with $\mathrm{Na}_{2} \mathrm{HPO}_{4}$ (solid), filtered, loaded $\left(3.5 \mathrm{~mL} \mathrm{~min}^{-1}\right)$ onto a $5 \mathrm{~mL}$ HisTrap Excel column (GE Healthcare, Little Chalfont, UK), washed with 25 column volumes (CV) $20 \mathrm{mM}$

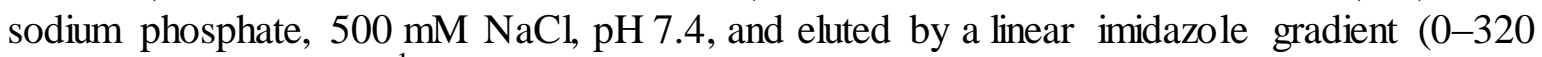
$\left.\mathrm{mM} ; 30 \mathrm{CV} ; 1 \mathrm{~mL} \mathrm{~min}^{-1}\right)$. Fractions $(1.92 \mathrm{~mL})$ were collected directly into $80 \mu \mathrm{L} 1 \mathrm{M}$ $\mathrm{MES} / \mathrm{NaOH}, 125 \mathrm{mM} \mathrm{CaCl}, 0.125 \%$ Triton X-100, $\mathrm{pH}$ 6.0. The resulting $\mathrm{pH} 6.5$ ensured $H v \mathrm{LD}$ stability. $H v \mathrm{LD}$-containing fractions were pooled, concentrated (4000 g, $30 \mathrm{kDa}$ cutoff, Amicon Ultra-15 centrifugal filter units; Millipore) and gel filtrated (Hiload 26/60 
Superdex 200 column; GE Healthcare) in $50 \mathrm{mM}$ MES/NaOH, $250 \mathrm{mM} \mathrm{NaCl}, 0.5 \mathrm{mM}$ $\mathrm{CaCl}_{2}, \mathrm{pH} 6.6\left(0.5 \mathrm{~mL} \mathrm{~min}^{-1}\right)$. Fractions containing pure $H v \mathrm{LD}$ (monitored by SDS-PAGE) were pooled and concentrated as above. Protein concentration was determined spectrophotometrically using a theoretical molar extinction coefficient, $\varepsilon_{280}=130180 \mathrm{M}^{-1} \mathrm{~cm}^{-}$ ${ }^{1}$ (ProtParam tool, ExPASy server; [53]). $H v \mathrm{LD}$ wild type and variants stocks were added $\mathrm{NaN}_{3}$ to $0.02 \%(\mathrm{w} / \mathrm{v})$ and stored at $4{ }^{\circ} \mathrm{C}$.

2.4. Enzyme activity

Initial rates of hydrolysis by $2.1-81 \mathrm{nM} H v \mathrm{LD}$ wild type and variants $(110 \mu \mathrm{L})$ of $0.02-$ $0.6 \mathrm{mg} \cdot \mathrm{mL}^{-1}$ pullulan (Megazyme), $0.23-10 \mathrm{mg} \cdot \mathrm{mL}^{-1}$ potato amylopectin (Sigma-Aldrich) and $0.2-5 \mathrm{mg} \cdot \mathrm{mL}^{-1} \beta$-limit dextrin (Megazyme) $(990 \mu \mathrm{L})$ in $20 \mathrm{mM}$ sodium acetate $\mathrm{pH} 5.5,5$ $\mathrm{mM} \mathrm{CaCl}, 0.005 \%$ Triton $\mathrm{X}-100$ at $37^{\circ} \mathrm{C}$ were determined using a reducing sugar assay $[18,19]$. Aliquots $(200 \mu \mathrm{L}$ for pullulan, $100 \mu \mathrm{L}$ for amylopectin; 20 and $50 \mu \mathrm{L}$ of $2-5$ and $0.5-1.5 \mathrm{mg} \cdot \mathrm{mL}^{-1} \beta$-limit dextrin, respectively) were removed after 3, 6, 9, 12, and $15 \mathrm{~min}$, mixed with $0.4 \mathrm{M}$ sodium carbonate $\mathrm{pH} 10.7,2.5 \mathrm{mM} \mathrm{CuSO}_{4}, 2.5 \mathrm{mM}$ 4,4-dicarboxy-1,2biquinoline, $6 \mathrm{mM}$ L-serine $(500 \mu \mathrm{L})$ to stop the reaction [54], followed by addition of Milli$\mathrm{Q}$ water to a final volume of $1 \mathrm{~mL}$, incubation $\left(80^{\circ} \mathrm{C}, 30 \mathrm{~min}\right)$ and absorbance measurement at $540 \mathrm{~nm}$ (Epoch Microplate Spectrophotometer, BioTek). Released reducing sugar was quantified using maltose $(0-55.5 \mu \mathrm{M})$ as standard. Kinetics were analysed in duplicates for wild type and variants except for the Ser14Arg, His109Arg and Phe620Ala/Asp621Ala variants obtained in very low yields and measured in single experiments. $K_{\mathrm{m}}$ and $k_{c a t}$ were determined by fitting the Michaelis-Menten equation (Eq. (1); amylopectin and $\beta$-limit dextrin) or the equation for uncompetitive substrate inhibition (Eq. (2); pullulan) to initial velocities [18,19] using the Enzyme Kinetics Module of the program Sigmaplot 14.0 (Systat Software, Chicago, USA). $K_{\mathrm{i}, \mathrm{s}}$ is the dissociation constant for the inhibitory substrateenzyme-substrate ternary complex.

$$
\begin{aligned}
& V=\frac{V_{\max }}{1+\frac{K_{\mathrm{m}}}{[\mathrm{s}]}} \\
& V_{\mathrm{i}, \mathrm{sub}}=\frac{V_{\max }}{1+\frac{K_{\mathrm{m}}}{[\mathrm{s}]}+\frac{[\mathrm{S}]}{K_{\mathrm{i}, \mathrm{s}}}}(2)
\end{aligned}
$$

Specific activity of $H v \mathrm{LD}$ wild type and variants $(3.6-27 \mathrm{nM})$ was determined on 0.4 $\mathrm{mg} \cdot \mathrm{mL}^{-1}$ pullulan essentially as described above. One Unit $\left(\mathrm{U}_{1}\right)$ is defined as the amount of enzyme releasing one micromole of reducing sugar per min under the assay conditions. Specific activity of $H v \mathrm{LD}$ wild type and variants $(50-107 \mathrm{nM})$ was also determined for 4,6$O$-benzylidene-4-nitrophenyl- $6^{3}$ - $\alpha$-D-maltotriosyl-maltotriose (BPNPG3G3; Megazyme). Enzyme $(30 \mu \mathrm{L})$ in $100 \mathrm{mM}$ sodium acetate, $\mathrm{pH} 5.5,0.05 \% \mathrm{BSA}, 0.02 \% \mathrm{NaN}_{3}$ was preincubated $\left(40^{\circ} \mathrm{C}, 5 \mathrm{~min}\right)$. The reaction was initiated by addition of $30 \mu \mathrm{L}$ PULL6G reagent containing substrate and stopped after $10 \mathrm{~min}$ by $900 \mu \mathrm{L} 2 \%$ Tris Base (w/v), pH 9.0.

Substrate consumption was quantified spectrophotometrically at $400 \mathrm{~nm}$ using 4-nitrophenol $(0.1-1 \mathrm{mM})$ as standard. One Unit $\left(\mathrm{U}_{2}\right)$ is defined as the amount of enzyme hydrolysing one micromole of substrate under the assay conditions.

\subsection{Surface plasmon resonance binding analysis of $\mathrm{HvLD}$-Phe553Gly}

The affinity of $H v \mathrm{LD}-\mathrm{Phe} 553 \mathrm{Gly}$ for $\beta$-CD was determined by surface plasmon resonance (SPR) (BIAcore ${ }^{\circledR T 100 ; ~ G E ~ H e a l t h c a r e, ~ S w e d e n) ~ a s ~ p r e v i o u s l y ~ d e s c r i b e d ~[18] . ~}$ $H v$ LD-Phe 553Gly was immobilized in the presence of $1 \mathrm{mM} \beta-\mathrm{CD}$ on a CM5 sensor chip (GE Healthcare, Sweden) by random amine coupling (1800 response units, RU). Binding to $\beta$-CD was tested by passing $1 \mathrm{mM} \beta-\mathrm{CD}$ in $20 \mathrm{mM}$ sodium acetate, $\mathrm{pH} 5.5,100 \mathrm{mM} \mathrm{NaCl}$, $0.005 \%$ surfactant $\mathrm{P}-20$ (running buffer) over the surface at $25^{\circ} \mathrm{C}$ using $3 \mathrm{~min}$ association and 2 min dissociation.

\section{Results and discussion}




\subsection{Bioinformatics and homology modelling of the $N$-terminal domain}

Sequence- and structure-based alignments and modelling were applied to evaluate which substitutions to do in the $H v$ LD N-terminal CBM21-like domain (residues 2-124) to assess the function of this domain for activity. One hundred homologs were identified using BLASTP having E-values between $2 \cdot 10^{-77}$ and $5 \cdot 10^{-31}, 95-100 \%$ query coverage, and 51$96 \%$ sequence similarity. Forty-two non-redundant sequences from seeds, fruits and flowers of plants and trees (Fig. 3) were annotated as PULs, LDs or hypothetical proteins, the majority being marked as predicted (Table S1). According to the CAZy database [5] only four proteins - sorghum, rice, wheat (Triticum aestivum L.) and $H v \mathrm{LD}$ - have been characterised. Comparison of the $H v \mathrm{LD}, S b \mathrm{LD}$ and $O s \mathrm{LD}$ sequences revealed that the rare allele variant of sorghum, $S b \mathrm{LD}-\mathrm{RA}$, found in grains containing highest amount of digestible starch [33] has arginines at positions corresponding to HvLD Ser14 and His 108 (6_ABK63626, Fig. 3). Notably, the most frequent sorghum allele, SbLD-GD, has glycine and aspartic acid (7_ABK63617, Fig. 3), which are not conserved in CBM21-like domains, corresponding to serine and alanine at $H v \mathrm{LD}$ positions 14 and 90 . In fact lysine and arginine commonly occur at the position corresponding to Ser14 in $H v$ LD (1_AAF98802, Fig. 3). $S b \mathrm{LD}-\mathrm{RA}$ and $H v \mathrm{LD}$ both have alanine at position 90 ( $H v \mathrm{LD}$ numbering). It is therefore hypothesized that arginine in SbLD-RA, matching Ser14 $H v \mathrm{LD}$, is responsible for higher PUL activity and more digestible starch in $S b$ LD-RA compared to $S b$ LD-GD, as measured using porcine enzymes as an in vitro proxy for monogastric digestion of starch from the rare allele sorghum homozygote [33]. Also a variant of the rice OsLD line (15_ACY56102, Fig. 3 ), which was associated with increased activity on branched substrates in developing seeds [34], has arginine aligned to $H v$ LD His 108 similarly to $S b$ LD-RA (Fig. 3).

The structural positioning of the residues in $S b L D-R A$ and $O s L D$ equal to Ser14, Ala90 and His108 of $H v$ LD was evaluated using the homology model, which showed only minor differences of $S b \mathrm{LD}-\mathrm{RA}$ and $O s \mathrm{LD}$ with respect to the overall structure of $H v \mathrm{LD}$ (PDB ID: 4AIO) and were evaluated as good to very good (Table S2). Alignment of all models with $H v$ LD (PDB ID: 4AIO) using PyMol 2.0 thus showed overall rmsd for $\mathrm{C} \alpha$ between 0.251 and $0.423 \AA$ (Table S2) and overlaying the SbLD-RA and OsLD models with the HvLD structure confirmed that counterparts of $H v$ LD Ser14, Ala90 and His 108 are exposed on the surface of the N-terminal CBM21-like domain (Fig. 4) approving our choice of the Ser14 and His108 for mutational analysis. The structural similarity of the $\mathrm{N}$-terminal domain of $H v \mathrm{LD}$ and CBM21 in $R$. oryzae glucoamylase was confirmed by the FATCAT database search (Table S5) and a DALI search (Table S6) although key residues of its two ligand binding sites were not conserved in $H v \mathrm{LD}$ [21].

\subsection{Impact of remote residues on the catalytic activity}

\subsection{1. $\quad N$-terminal CBM21-like domain mutants}

Kinetic parameters towards pullulan, amylopectin and $\beta$-limit dextrin confirmed that $H v \mathrm{LD}$ has much higher (150-fold) catalytic efficiency towards pullulan than amylopectin (Table 1). Moreover, for $\beta$-limit dextrin, which is an important natural substrate for cereal LDs/PULs, lower $K_{\mathrm{m}}$ and higher $k_{\text {cat }}$ yield 6.5 -fold higher catalytic efficiency than for amylopectin. This is in excellent agreement with LDs having preference for branched maltooligosaccharides, also referred to as $\alpha$-limit dextrins. The function and possible involvement of the $\mathrm{N}$-terminal domain in the activity towards amylopectin was investigated using three different $H v \mathrm{LD}$ mutants. Firstly, the previously

Fig. 3. Multiple sequence alignment of the N-terminal domain (residues 2-124) of $H v \mathrm{LD}$ and homologue sequences obtained from a BLAST search using the $H v L D$ N-terminal CBM21-like domain as query (top line). Strictly conserved, white letters with red background; $>70 \%$ conservation, red and framed blue. Position 
numbers correspond to the $H v \mathrm{LD}$ sequence. Note the numbering is shifted by one in the $H v \mathrm{LD}$ structures referred in the text due to one extra residue starting at the N-terminal sequence originating from the used vector for recombinant protein expression [18]. Hence residue 13 in the sequence is identical to residue 14 in the structures and so forth. Sequences from sorghum and rice are highlighted in pink and green, respectively. The positions of the $H v \mathrm{LD}$ residues Ser14, Ala90, and His 108 mutated in rice and sorghum LD variants are marked by asterisks and coloured according to their origin. Table S1 shows GenBank accessions and organis ms. The alignment was visualised using ESPript [39].

Fig. 4. Comparis on of homology models of $S b L D-R A$ and $O s L D$ 93-11 with the $H v L D$ structure. (A) Superimposition of N-terminal domains of $H v \mathrm{LD}$ (PDB ID: 4AIO, grey), and homology models of $S b \mathrm{LD}-\mathrm{RA}$ (NCBI: ABK63626.1; violet) and OsLD 93-11 (NCBI: EEC76742.1; splitpea). Residues corresponding to $H v \mathrm{LD}$ Ser14, Ala90 and His 108 (observe that the side chain of this residue is not completely solved in the crystal structure due to lack of electron density [21]) in the sorghum and rice models are shown as sticks and labelled according to origin following the same colour code. (B) Surface representation of $H v L D$ with the three $\mathrm{N}$-terminal domain residues highlighted in orange and active site residues in blue.

\begin{tabular}{|c|c|c|c|c|c|c|c|c|c|c|}
\hline \multirow[b]{2}{*}{$H v L D$} & \multicolumn{4}{|c|}{ Pullulan $^{\mathrm{a}}$} & \multicolumn{3}{|c|}{ Amylopectin $^{6}$} & \multicolumn{3}{|c|}{$\beta$-limit dextrin ${ }^{b}$} \\
\hline & $\begin{array}{c}K_{\mathrm{m}} \\
\mathrm{mg} / \mathrm{mL}\end{array}$ & $\begin{array}{c}k_{\mathrm{cat}} \\
\mathrm{s}^{-1} \\
\end{array}$ & $\begin{array}{c}k_{\text {cat }} / K_{\mathrm{m}} \\
\mathrm{mL} /(\mathrm{mg} \quad \mathrm{s})\end{array}$ & $\begin{array}{c}K_{\mathrm{i}, \mathrm{s}} \\
\mathrm{mg} / \mathrm{mL}\end{array}$ & $\begin{array}{c}K_{\mathrm{m}} \\
\mathrm{mg} / \mathrm{mL}\end{array}$ & $\begin{array}{c}k_{\text {cat }} \\
\mathrm{s}^{-1}\end{array}$ & $\begin{array}{c}k_{\text {cat }} / K_{\mathrm{m}} \\
\mathrm{mL}(\mathrm{mg} \quad \mathrm{s})\end{array}$ & $\begin{array}{c}K_{\mathrm{m}} \\
\mathrm{mg} / \mathrm{mL}\end{array}$ & $\begin{array}{c}k_{\text {cat }} \\
\mathrm{s}^{-1}\end{array}$ & $\begin{array}{c}k_{\text {cat }} / K_{\mathrm{m}} \\
\mathrm{mL} /(\mathrm{mg} \quad \mathrm{s})\end{array}$ \\
\hline wild type & $0.08 \pm 0.008$ & $24 \pm 1.3$ & $300 \pm 34$ & $2.0 \pm 0.6$ & $4.8 \pm 0.7$ & $9.4 \pm 0.6$ & $2.0 \pm 0.3$ & $2.7 \pm 0.2$ & $35 \pm 1.4$ & $13 \pm 1.1$ \\
\hline Ser14Arg* & $0.1 \pm 0.02$ & $6.3 \pm 0.6$ & $63 \pm 14$ & $2.7 \pm 1.6$ & $2.6 \pm 0.8$ & $1.7 \pm 0.2$ & $0.7 \pm 0.2$ & $2.3 \pm 0.4$ & $6.3 \pm 0.5$ & $2.7 \pm 0.5$ \\
\hline His 108Arg* & $0.2 \pm 0.03$ & $9.0 \pm 1.0$ & $45 \pm 8$ & $0.9 \pm 0.3$ & $4.5 \pm 1.0$ & $2.3 \pm 0.2$ & $0.5 \pm 0.1$ & $2.8 \pm 1.4$ & $11 \pm 3.1$ & $3.9 \pm 2.2$ \\
\hline $\begin{array}{l}\text { Ser14Arg/ } \\
\text { His108Arg }\end{array}$ & $0.1 \pm 0.01$ & $19 \pm 1.5$ & $190 \pm 24$ & $1.3 \pm 0.4$ & $6.5 \pm 0.6$ & $7.4 \pm 0.4$ & $1.3 \pm 0.1$ & $5.2 \pm 0.5$ & $18 \pm 1.0$ & $3.5 \pm 0.4$ \\
\hline Phe620Ala & $0.09 \pm 0.02$ & $18 \pm 1.7$ & $200 \pm 48$ & $2.7 \pm 1.4$ & $7.6 \pm 1.3$ & $12 \pm 1.1$ & $1.6 \pm 0.3$ & $3.8 \pm 0.5$ & $33 \pm 2.7$ & $8.7 \pm 1.3$ \\
\hline Asp621Ala & $0.12 \pm 0.01$ & $56 \pm 2.7$ & $467 \pm 45$ & $3.6 \pm 0.5$ & $11 \pm 1.8$ & $15 \pm 1.5$ & $1.4 \pm 0.3$ & $4.8 \pm 0.7$ & $37 \pm 3.2$ & $7.7 \pm 1.3$ \\
\hline $\begin{array}{l}\text { Phe620Ala } \\
\text { /Asp621Ala* }\end{array}$ & $0.09 \pm 0.01$ & $3.8 \pm 0.3$ & $42 \pm 6$ & $1.6 \pm 0.6$ & n.d. & - & - & n.d. & - & - \\
\hline
\end{tabular}

Table 1 Kinetic parameters of $H v \mathrm{LD}$ wild type and mutants in the CBM21-like N-terminal domain (Ser14 and His 108) and at remote main chain binding subsite +3 (Phe620 and Asp621) of the active site towards pullulan, amylopectin and $\beta$-limit dextrin. ${ }^{a}$ Uncompetitive substrate inhibition, ${ }^{b}$ Classical Michaelis-Menten equation. Due to very low $H v \mathrm{LD}$ mutant protein yields, the activity was not determined for some substrates (n.d.) or only determined from single experiments $(*)$. Standard deviations refer to deviations from the fitted model.

reported sorghum SbLD-RA from seeds with high debranching activity and more digestible starch [33], was mimicked by $H \nu$ LD-Ser14Arg, which, compared to wild type, lost 65-80\% catalytic efficiency for the three polysaccharides mostly due to reduced $k_{\text {cat }}$ (Table 1). Moreover, $H v$ LD-His108Arg lost 70-85\% catalytic efficiency for the polysaccharide substrates also mostly due to reduced $k_{\text {cat }}$, and emulated $O s L D$ displaying increased zymograph degradation of amylopectin [34]. For both mutants the decrease in catalytic efficiencies (Table 1) and specific activities (Fig. 5A) was similar for amylopectin, $\beta$-limit dextrin and pullulan, while the activity of the double mutant $H v \mathrm{LD}-\mathrm{Ser} 14 \mathrm{Arg} / \mathrm{His} 108 \mathrm{Arg}$ decreased by only $35-37 \%$ activity for pullulan and amylopectin, though by $73 \%$ for $\beta$-limit dextrin similarly to the single mutants (Fig. 5A). The possibility of Ser14 and His108 exerting a long-range impact on the active site in $H v \mathrm{LD}$ was assessed from their reduced mutant activity on the hexasaccharide BPNPG3G3 presumed to bind at subsites +1 through +3 and -1 through -3 , placing the scissile $\alpha$-1,6-bond between subsites +1 and -1 . Relative to wild type, $H v$ LD-Ser14Arg and $H v$ LD-His 108 Arg were $49 \%$ and $32 \%$ less active on BPNPG3G3 compared to loss of $71 \%$ and $47 \%$ activity, respectively for pullulan (Fig. 5A). The double mutant $H v$ LD-Ser14Arg/His 108 Arg compensated and had the same specific activity (109\%) as wild type on BPNPG3G3, but lost some, albeit less activity than the single mutants on the polysaccharides (Fig. 
Fig. 5. Specific activities of $H v \mathrm{LD}$ wild type and mutants on pullulan, amylopectin, $\beta$-limit dextrin and BPNPG3G3. (A) N-terminal domain mutants. (B) Subsites +2 and +3 mutants. See Table $\mathrm{S} 7$ for the specific acitivties given in $\mathrm{U} / \mathrm{mg}$. Activity was not determined of Phe553Gly on amylopectin and $\beta$-limit dextrin as well as of Asp621Ala on BNPG3G3.

5A). Glucoamylase CBM21 contains two CD binding sites [26] and two flexible loops participating in the sugar binding [55]. This makes us speculate that substrate binding triggered some favourable conformational adjustment of the double $H v \mathrm{LD}$ mutant. Notably, $H v$ LD-Ser14Arg/His $108 \mathrm{Arg}$ and $H v$ LD-His108Arg were both also significantly more prone to substrate inhibition by pullulan (Table 1). Overall, the enzymatic properties of the mutants in the CBM21-like domain indicate an involvement in maintaining $H v \mathrm{LD}$ activity, as generally envisaged for a multidomain enzyme [56-58]. The larger losses of activity towards pullulan, amylopectin and $\beta$-limit dextrin compared to the oligosaccharide substrate is in agreement with polysaccharides more readily perceiving changes at a remote area of the protein surface.

3.2.2. $\quad$ Substrate main chain binding subsites +2 and +3 at the active site

Insights into substrate interactions at the active site of debranching enzymes have been particularly difficult to obtain and only one structure, namely that of $H v \mathrm{LD}$ was determined of a branched substrate complex [19]. Knowledge still lacks, however, on how glucosyl residues of the substrate main chain at some distance of the subsites +1 and -1 , encompassing the site of catalysis, contribute to substrate specificity. In HvLD Trp512, Phe553, Phe620 and Asp621 appear critical at subsites +2 and +3 (Fig. 2). Thus to compare side chains accommodating substrate main chain at these subsites, a structure-based multiple sequence alignment was carried out for debranching enzymes of GH13_11, i.e. isoamylases, GH13_12-14 PULIs, and GH13_39 PULII (Fig. 6; for full sequence alignment see Fig. S1 and for corresponding organisms see Table S3).

$H v$ LD Trp512 at subsite +2 is invariant in the structural alignment of GH13_11-14 and GH13_39 (Fig. 6) in agreement with earlier findings [6]. Therefore Trp512 is not considered useful for mutational analysis of specificity determinants. Phe553, however, is not generally conserved in GH13, and previously, it was shown that a structure-based multiple sequence alignment does not bring the amino acid residues of other PULIs equivalent to Phe553 in perfect alignment (Fig. 6).

Fig. 6. Excerpt of structure-based sequence alignment of is oamylases of GH13_11, PULs of GH13_12-14 and PULIIs of GH13_39 (See Fig. S1 for full alignment and Table S3 for organisms). Protein structures were used for the alignment except for GH13_39, where GH13_39 protein sequences from selected characterized enzymes were included as no structures were available from the subfamily. The numbering above the alignment corresponds to the $H v \mathrm{LD}$ structure numbering (PDB ID: 4AIO) . Fully conserved residues are in white letters on red background and $70 \%$ conservation is in red letters in a blue box. Residues corresponding to $H v \mathrm{LD} \operatorname{Trp512}$, Phe553, Phe620 and Asp621 are in green boxes. The alignment was visualised using ESPript [39].

Fig. 7. Comparis on of $H v \mathrm{LD}\left(\mathrm{GH} 13 \_13\right)$ and is oamylases (GH13_11). $H v \mathrm{LD}$ (PDB ID: 4AIO; grey) shown with $6^{3}-\alpha$-D-glucosyl-maltotriosyl-maltotriose $\left(\mathrm{GG}^{2} 3 \mathrm{G}^{2} 3\right.$; pink sticks) from the $H v \mathrm{LD}$ complex structure (PDB ID: 4J3X). Asp600-Leu622 loop (pink); Phe620 and Asp621 (violet-purple sticks); Trp512 and Phe553 (deep blue sticks). Isoamylase 1 (GH13_11) from Chlamydomonas Reinhardtii (PDB ID: 4J7R; green); isoamylase/4$\alpha$-glucanotransferase (GH13_11) from Sulfolobus Solfataricus (PDB ID: 2VNC; bright orange).

However, a superposition of the structures from GH13_12-14 showed that the residues corresponding to Phe553 occupied the same three-dimensional space [19]. In a few cases sequence alignments show glycine or tyrosine at this position [19]. GH13_11 and GH13_39 debranching enzymes are lacking the loop where Phe553 is situated (Fig. 6). Phe553 intrudes 
into the central cavity of CD inhibitors in $H v \mathrm{LD}$ complexes [19,24] and $H v$ LD-Phe553Gly was made to interrogate the importance of this aromatic side chain.

The structure-based alignment furthermore showed that the long loop from $\alpha 6$ to $\beta 7$ in $H v \mathrm{LD}$ (Asp600-Leu622) of GH13_13 is absent in GH13_12 and 14 [19]. The loop, however, exists in one GH13_11 isoamylase from Chlamydomonas reinhardtii (PDB ID: 4J7R) [59] (Fig. 6), but adopts a different position in that enzyme than in $H v \mathrm{LD}$ (Fig. 7). Both Phe620 and Asp621 from this loop are conserved in GH13_13 PULIs; Phe620 can be Phe, Tyr or His, while Asp621 is an Asn [19]. Phe620 and Asp621 are situated near subsite +3 in the complex of $H v \mathrm{LD}$ with G2S $\beta C D$ (PDB ID: 4J3U) [20] and therefore assigned a role in substrate binding, presumably accommodating the third glucosyl residue towards the reducing end from the $\alpha-1,6$ scissile bond. The electron density of Phe620 and Asp621 at subsite +3 is in some of the available $H v \mathrm{LD}$ structures lacking for both or just one of the side chains. Only in the structure with G2S $\beta C D$ (PDB ID: 4J3U) Phe620 is seen to interact with the CD ring. Asp621 is interacing with ligand in the maltotetraose containing structures (PDB ID: 4J3S and 4J3T), while it is present in the structure with G2S $\beta C D$ (PDB ID: 4J3U), but it is not interacting with the ligand. In the complex with $\mathrm{G} 2 \mathrm{~S} \beta \mathrm{CD}$, the loop backbone is twisted differently than in the rest of the available $H v$ LD structures. Based on these different observations, the loop is thought to be flexible [19]. The loop and Phe620 are not conserved in subfamilies GH13_12 and GH13_14 and generally lack in most of the GH13 subfamilies included in the structure-based alignment in Fig. 6. Thus HvLD Phe620Ala, Asp621Ala and the double mutant Phe620Ala/Asp621Ala, were made to explore the role of these loop residues for activity on poly- and oligosaccharide substrates.

\subsection{3. $\quad$ Subsite +2 and +3 mutants}

$H v$ LD-Phe 553Gly targeting the substrate main chain binding at subsite +2 lost $53 \%$ specific activity towards pullulan and 75\% towards BPNPG3G3 (Fig. 5B). The oligosaccharide substrate obviously depends more strongly on the specific binding at subsite +2. SPR analysis confirmed that Phe553Gly was unable to bind $\beta$-CD. When binding to 1 $\mathrm{mM} \beta-\mathrm{CD}$ was tested no significant signal, hence no binding was detected, while the affinity of wild-type $H v \mathrm{LD}$ is excellent with $K_{\mathrm{d}}=0.7 \mu \mathrm{M}$ [18], thus the affinity must have been lost by a factor of more than 3 orders of magnitude. Recently, an important role in activity was also reported for Phe746 in K. pneumoniae PULI [28] that is equivalent to $H v$ LD Phe553. Thus $K_{\mathrm{i}}$ for inhibition of Phe746Ala of $K$. pneumoniae PULI by $\beta$-CD increased 1,700 -fold compared to the wild type enzyme.

The catalytic efficiency of the subsite +3 mutant $H v$ LD-Phe620Ala was reduced by only 33,20 , and $33 \%$ on pullulan, amylopectin, and $\beta$-limit dextrin, respectively (Table 1). The $k_{\text {cat }}$ value on pullulan was reduced by $25 \%$ while the $K_{\mathrm{m}}$ was unchanged, whereas on amylopectin $k_{\text {cat }}$ increased by $28 \%$ and $K_{\mathrm{m}}$ increased by $58 \%$. For $H v$ LD-Asp621 Ala, noticeably the catalytic efficiency on pullulan was increased by $58 \%$, while it was reduced about $30 \%$ on amylopectin and $\beta$-limit dextrin. These changes in catalytic efficiency in case of pullulan are due to increased $k_{\text {cat }}$, while $K_{\mathrm{m}}$ on amylopectin and $\beta$-limit dextrin increased by $133 \%$ and $40 \%$, respectively, and $k_{\text {cat }}$ by $60 \%$ and $6 \%$, respectively (Table 1 ). Hence, Asp621 is a substrate preference determinant discriminating between the natural branched substrates and the linear model substrate pullulan. The double mutant Phe620Ala/Asp621Ala, however, retained only $14 \%$ residual activity on pullulan and even less, 7 and $9 \%$, towards amylopectin and $\beta$-limit dextrin (Table 1 and Fig. 5). The relatively higher activity on BPNPG3G3 of 57\% and 25\% seen for Phe620Ala and Phe620Ala/Asp621Ala, respectively (Fig. 5B), moreover, emphasises the different importance of subsites +2 and +3 for the activity on oligosaccharide substrate. The combination of Phe620 and Asp621 is particularly 
important for activity on branched polysaccharides and loss of activity was less dramatic if only Phe620 is substituted.

\section{Conclusion}

Using $H v \mathrm{LD}$ as a model and implementing mutations imitating positions tentatively associated with high activity sorghum and rice variants, it was demonstrated that the $\mathrm{N}$ terminal CBM21-like domain of $H \nu \mathrm{LD}$ indeed plays a role in activity and possibly possesses a characteristic high level of dynamics similarly to structure-determined CBM21 domains. The results indicated that the targeted surface exposed residues of the N-terminal CBM21like domain have a role for hydrolysis of polysaccharide substrates and also of a branched oligosaccharide. In the latter case one may envisage a conformational change as a result of the mutations resulting in a long distance effect on the active site or an allosteric stimulation of activity by substrate binding at a remote site on the protein surface. However, carbohydrate binding to the domain has not been demonstrated experimentally. $H v \mathrm{LD}$ is the only LD or PUL for which a structure of a substrate complex has been determined, and the present mutational analysis strongly supports that the Trp512-Phe553 aromatic sandwich at subsite +2 is especially critical for activity on oligosaccharides, while both Phe620 and Asp621 at subsite +3 are important in particular for polysaccharide degradation and discriminate between pullulan and the two branched polysaccharides. These latter characteristics may also have functional relevance for LDs (GH13_13) as opposed to PULs (GH13_12 and GH13_14) in agreement with the low degree of sequence conservation between these enzymes in this active site region. Finally, this first kinetic analysis on $H v \mathrm{LD}$ degrading $\beta$-limit dextrin, that presumably is a natural substrate for $\mathrm{LD}$, showed a preference over amylopectin, although $K_{\mathrm{m}}$ and $k_{\text {cat }}$ were still 25 -fold higher and 9-fold lower, respectively, than for pullulan.

\section{Acknowledgements}

Karina Jansen and Julia Tanas Tanasi are thanked for expert technical assistance and Tobias Hegelund Olsen for experimental work during his bachelor thesis.

\section{Funding}

This work was supported the Independent Research Fund Denmark | Natural Sciences (FNU; 6108-00476A) and Independent Research Fund Denmark | Technology and Production Sciences (FTP; DFF-1337-00158) and by a PhD scholarship at The Technical University of Denmark (S.A.).

\section{Conflict of interest}

The authors declare that they have no conflicts of interest with the contents of this article.

\section{Author contributions}

SA: Investigation, Formal Analysis, Writing - Original draft preparation, Writing Reviewing and Editing, Visualisation. BS: Conceptualization, Writing - Reviewing and Editing, Supervision, Funding Acquisition. MSM: Conceptualization, Investigation, Formal Analysis, Writing - Reviewing and Editing, Visualisation

\section{Appendix A. Supplementary data}

Supplementary data to this acticle can be found online at XXX. 


\section{References}

[1] E. Bertoft, Understanding starch structure: recent progress, Agron. J., 7 (2017) 1-29.

[2] M.K. Morell, C. Konik-Rose, R. Ahmed, Z. Li, S. Rahman, Synthesis of resistant starches in plants, J. AOAC Int., 87 (2004) 740-748.

[3] S.C. Zeeman, J. Kossmann, A.M. Smith, Starch: Its metabolism, evolution, and biotechnological modification in plants, Annu. Rev. Plant Biol., 61 (2010) 209-234.

[4] V. Vamadevan, E. Bertoft, Structure-function relationships of starch components, Starch/Staerke, 67 (2015) 55-68.

[5] V. Lombard, H. Golaconda Ramulu, E. Drula, P.M. Coutinho, B. Henrissat, The carbohydrate-active enzymes database (CAZy) in 2013, Nucleic Acids Res., 42 (2014) 490-495.

[6] E.A. MacGregor, Š. Janeček, B. Svensson, Relationship of sequence and structure to specificity in the $\alpha$-amylase family of enzymes, Biochim. Biophys. Acta - Protein Struct. Mol. Enzymol., 1546 (2001) 1-20.

[7] M.R. Stam, E.G.J. Danchin, C. Rancurel, P.M. Coutinho, B. Henrissat, Dividing the large glycoside hydrolase family 13 into subfamilies: Towards improved functional annotations of $\alpha$-amylase-related proteins, Protein Eng. Des. Sel., 19 (2006) 555-562.

[8] M.S. Møller, A. Henriksen, B. Svensson, Structure and function of $\alpha$-glucan debranching enzymes, Cell. Mol. Life Sci., 73 (2016) 2619-2641.

[9] D.J. Manners, D. Yellowlees, Studies on carbohydrate metabolising enzymes, Die Stärke, 23 (1971) 228-234.

[10] A.W. MacGregor, $\alpha$-Amylase, limit dextrinase, and $\alpha$-glucosidase enzymes in barley and malt, Crit. Rev. Biotechnol. 5 (1987) 117-128.

[11] R.S. Singh, G.K. Saini, J.F. Kennedy, Pullulan: Microbial sources, production and applications, Carbohydr. Polym., 73 (2008) 515-531.

[12] Z. Sun, C.A. Henson, A quantitative assessment of the importance of barley seed $\alpha-$ amylase, $\beta$-amylase, debranching enzyme, and $\alpha$-glucosidase in starch degradation, Arch. Biochem. Biophys., 284 (1991) 298-305.

[13] T.P. Frandsen, B. Svensson, Plant $\alpha$-glucosidases of the glycoside hydrolase family 31. Molecular properties, substrate specificity, reaction mechanism, and comparison with family members of different origin, Plant Mol.Biol., 37 (1998) 1-13.

[14] M. Kristensen, F. Lok, V. Planchot, I. Svendsen, R. Leah, B. Svensson, Isolation and characterization of the gene encoding the starch debranching enzyme limit dextrinase from germinating barley, Biochim. Biophys. Acta, 1431 (1999) 538-546.

[15] V.V. Radchuk, L. Borisjuk, N. Sreenivasulu, K. Merx, H.-P. Mock, H. Rolletschek, U. Wobus, W. Weschke, Spatiotemporal profiling of starch biosynthesis and degradation in the developing barley grain, Plant Physiol., 150 (2009) 190-204.

[16] D. Stanley, M. Rejzek, H. Naested, M. Smedley, S. Otero, B. Fahy, F. Thorpe, R.J. Nash, W. Harwood, B. Svensson, K. Denyer, R.A. Field, A.M. Smith, The role of $\alpha-$ glucosidase in germinating barley grains, Plant Physiol., 155 (2011) 932-943.

[17] H. Hussain, A. Mant, R. Seale, S. Zeeman, E. Hinchliffe, A. Edwards, C. Hylton, S. Bornemann, A.M. Smith, C. Martin, R. Bustos, Three isoforms of isoamylase contribute different catalytic properties for the debranching of potato glucans, Plant Cell, 15 (2003) 133-149.

[18] M.B. Vester-Christensen, M. Abou Hachem, H. Naested, B. Svensson, Secretory expression of functional barley limit dextrinase by Pichia pastoris using high celldensity fermentation, Protein Expr. Purif., 69 (2010) 112-119.

[19] M.S. Møller, M.S. Windahl, L. Sim, M. Bøjstrup, M. Abou Hachem, O. Hindsgaul, M. Palcic, B. Svensson, A. Henriksen, Oligosaccharide and substrate binding in the starch 
debranching enzyme barley limit dextrinase, J. Mol. Biol., 427 (2015) 1263-1277.

[20] T. Ashikari, N. Nakamura, Y. Tanaka, N. Kiuchi, Y. Shibano, T. Tanaka, Rhizopus raw-starch-degrading glucoamylase: its cloning and expression in yeast, Agric. Biol. Chem., 50 (1986) 957-964.

[21] M.S. Møller, M. Abou Hachem, B. Svensson, A. Henriksen, Structure of the starchdebranching enzyme barley limit dextrinase reveals homology of the N-terminal domain to CBM21, Acta Crystallogr. Sect. F. Struct. Biol. Cryst. Commun., 68 (2012) 1008-1012.

[22] M. Machovič, Š. Janeček, Domain evolution in the GH13 pullulanase subfamily with focus on the carbohydrate-binding module family 48, Biologia (Bratisl)., 63 (2008) 1057-1068.

[23] C. Wilkens, B. Svensson, M. Møller, Functional roles of starch binding domains and surface binding sites in enzymes involved in starch biosynthesis, Front. Plant Sci., 9 (2018) 1-12.

[24] M.B. Vester-Christensen, M. Abou Hachem, B. Svensson, A. Henriksen, Crystal structure of an essential enzyme in seed starch degradation: barley limit dextrinase in complex with cyclodextrins, J. Mol. Biol., 403 (2010) 739-750.

[25] M.S. Møller, B. Svensson, Structural biology of starch-degrading enzymes and their regulation, Curr. Opin. Struct. Biol., 40 (2016) 33-42.

[26] Y. Liu, Y. Lai, W. Chou, M.D. Chang, P. Lyu, Solution structure of family 21 carbohydrate-binding module from Rhizopus oryzae glucoamylase, Biochem. J., 403 (2007) 21-30.

[27] A. Lammerts Van Bueren, E. Ficko-Blean, B. Pluvinage, J.H. Hehemann, M.A. Higgins, L. Deng, A.D. Ogunniyi, U.H. Stroeher, N. El Warry, R.D. Burke, M. Czjzek, J.C. Paton, D.J. Vocadlo, A.B. Boraston, The conformation and function of a multimodular glycogen-degrading pneumococcal virulence factor, Structure, 19 (2011) 640-651.

[28] N. Saka, H. Iwamoto, D. Malle, N. Takahashi, K. Mizutani, B. Mikami, Elucidation of the mechanism of interaction between Klebsiella pneumoniae pullulanase and cyclodextrin, Acta Crystallogr. Sect. D Struct. Biol., 74 (2018) 1115-1123.

[29] J. Xu, F. Ren, C.H. Huang, Y. Zheng, J. Zhen, H. Sun, T.P. Ko, M. He, C.C. Chen, H.C. Chan, R.T. Guo, H. Song, Y. Ma, Functional and structural studies of pullulanase from Anoxybacillus sp LM18-11, Proteins: Struct. Funct. Bioinf., 82 (2014) 16851693.

[30] D. Cockburn, B. Svensson, Surface binding sites in carbohydrate active enzymes: an emerging picture of structural and functional diversity, Carbohydr. Chem., (2013) 204-221.

[31] D. Cockburn, C. Wilkens, A. Dilokpimol, H. Nakai, A. Lewińska, M. Abou Hachem, B. Svensson, Using carbohydrate interaction assays to reveal novel binding sites in carbohydrate active enzymes, PLoS One, 11 (2016) 1-18.

[32] D. Cockburn, M.M. Nielsen, C. Christiansen, J.M. Andersen, J.B. Rannes, A. Blennow, B. Svensson, Surface binding sites in amylase have distinct roles in recognition of starch structure motifs and degradation, Int. J. Biol. Macromol., 75 (2015) 338-345.

[33] E.K. Gilding, C.H. Frère, A. Cruickshank, A.K. Rada, P.J. Prentis, A.M. Mudge, E.S. Mace, D.R. Jordan, I.D. Godwin, Allelic variation at a single gene increases food value in a drought-tolerant staple cereal, Nat. Commun., 4 (2013) 1-6.

[34] Y. Chen, J. Bao, Underlying mechanisms of zymographic diversity in starch synthase I and pullulanase in rice developing endosperm, J. Agric. Food Chem., 9 (2016) 2030- 
2037.

[35] V. Kumar, Analysis of the key active subsites of glycoside hydrolase 13 family members, Carbohydr. Res., 345 (2010) 893-898.

[36] T. Kuriki, H. Kaneko, M. Yanase, H. Takata, J. Shimada, S. Handa, T. Takada, H. Umeyama, S. Okada, Controlling substrate preference and transglycosylation activity of neopullulanase by manipulating steric constraint and hydrophobicity in active center, J. Biol. Chem., 271 (1996) 17321-17329.

[37] S.F. Altschul, J.C. Wootton, E.M. Gertz, R. Agarwala, A. Morgulis, A.A. Schäffer, Y.K. Yu, Protein database searches using compositionally adjusted substitution matrices, FEBS J., 272 (2005) 5101-5109.

[38] K. Katoh, D.M. Standley, MAFFT multiple sequence alignment software version 7: Improvements in performance and usability, Mol. Biol. Evol., 30 (2013) 772-780.

[39] X. Robert, P. Gouet, Deciphering key features in protein structures with the new ENDscript server, Nucleic Acids Res., 42 (2014) 320-324.

[40] A. Marchler-Bauer, J.B. Anderson, F. Chitsaz, M.K. Derbyshire, C. DeWeese-Scott, J.H. Fong, L.Y. Geer, R.C. Geer, N.R. Gonzales, M. Gwadz, S. He, D.I. Hurwitz, J.D. Jackson, Z. Ke, C.J. Lanczycki, C. a Liebert, C. Liu, F. Lu, S. Lu, G.H. Marchler, et al., CDD: specific functional annotation with the Conserved Domain Database, Nucleic Acids Res., 37 (2009) D205-D210.

[41] Y. Yin, X. Mao, J. Yang, X. Chen, F. Mao, Y. Xu, DbCAN: A web resource for automated carbohydrate-active enzyme annotation, Nucleic Acids Res., 40 (2012) $445-451$.

[42] L. Zimmermann, A. Stephens, S.Z. Nam, D. Rau, J. Kübler, M. Lozajic, F. Gabler, J. Söding, A.N. Lupas, V. Alva, A completely reimplemented MPI bioinformatics toolkit with a new HHpred server at its core, J. Mol. Biol., 430 (2018) 2237-2243.

[43] B. Webb, A. Sali, S. Francisco, Comparative protein structure modeling using MODELLER, Curr. Protoc. Bioinforma., 54 (2017) 1-55.

[44] M. Biasini, S. Bienert, A. Waterhouse, K. Arnold, G. Studer, T. Schmidt, F. Kiefer, T.G. Cassarino, M. Bertoni, L. Bordoli, T. Schwede, SWISS-MODEL: Modelling protein tertiary and quaternary structure using evolutionary information, Nucleic Acids Res., 42 (2014) 252-258.

[45] B. Wallner, A. Elofsson, Can correct protein models be identified?, Protein Sci., 12 (2003) 1073-1086.

[46] Y. Ye, A. Godzik, Flexible structure alignment by chaining aligned fragment pairs allowing twists, Bioinformatics, 19 (2003) ii246-255.

[47] L. Holm, P. Rosenström, Dali server: conservation mapping in 3D, Nucleic Acids Res., 38 (2010) W545-W549.

[48] J. Pei, B.H. Kim, N. V. Grishin, PROMALS3D: A tool for multiple protein sequence and structure alignments, Nucleic Acids Res., 36 (2008) 2295-2300.

[49] Y. Nakata, X. Tang, K.K. Yokoyama, Preparation of competent cells for highefficiency plasmid transformation of Escherichia coli, Methods Mol. Biol., 69 (1997) 129-137.

[50] H.E.N. Bergmans, I.M. Van Die, W.P.M. Hoekstra, Transformation in Escherichia coli: stages in the process, J. Bacteriol., 146 (1981) 564-570.

[51] B.V. McCleary, Measurement of the content of limit-dextrinase in cereal flours, Carbohydr. Res., 227 (1992) 257-268.

[52] M. Kristensen, V. Planchot, J. Abe, B. Svensson, Large-scale purification and characterization of barley limit dextrinase, a member of the $\alpha$-amylase structural family, Cereal Chem., 75 (1998) 473-479. 
[53] E. Gasteiger, A. Gattiker, C. Hoogland, I. Ivanyi, R.D. Appel, A. Bairoch, R.M. Servet, ExPASy: the proteomics server for in-depth protein knowledge and analysis, Nucleic Acids Res., 31 (2003) 3784-3788.

[54] K. Mopper, E. Melvin Gindler, A new noncorrosive dye reagent for automatic sugar chromatography, Anal. Biochem., 56 (1973) 440-442.

[55] J.-Y. Tung, M.D.-T. Chang, W.-I. Chou, Y.-Y. Liu, Y.-H. Yeh, F.-Y. Chang, S.-C. Lin, Z.-L. Qiu, Y.-J. Sun, Crystal structures of the starch-binding domain from Rhizopus oryzae glucoamylase reveal a polysaccharide-binding path, Biochem. J., 416 (2008) 27-36.

[56] J. Wang, Z. Liu, Z. Zhou, The N-terminal domain of the pullulanase from Anoxybacillus sp WB42 modulates enzyme specificity and thermostability, ChemBioChem, 19 (2018) 949-955.

[57] L. Li, F. Dong, L. Lin, D. He, W. Wei, D. Wei, N-terminal domain truncation and domain insertion-based engineering of a novel thermostable type I pullulanase from Geobacillus thermocatenulatus, J. Agric. Food Chem., 66 (2018) 10788-10798.

[58] X. Duan, J. Wu, Enhancing the secretion efficiency and thermostability of a Bacillus deramificans pullulanase mutant (D437H/D503Y) by N-terminal domain truncation, Appl. Environ. Microbiol., 81 (2015) 1926-1931.

[59] L. Sim, S.R. Beeren, J. Findinier, D. Dauville, S. Ball, A. Henriksen, M.M. Palcic Crystal structure of the Chlamydomonas starch debranching enzyme isoamylase ISA1 reveals insights into the mechanism of branch trimming and complex assembly, J. Biol. Chem. 289 (2014) 22991-23003.

[60] E.J. Woo, S. Lee, H. Cha, J.T. Park, S.M. Yoon, H.N. Song, K.H. Park, Structural insight into the bifunctional mechanism of the glycogen-debranching enzyme TreX from the archaeon Sulfolobus solfataricus, J. Biol. Chem., 283 (2008) 28641-28648.

[61] H.N. Song, T.Y. Jung, J.T. Park, B.C. Park, P.K. Myung, W. Boos, E.J. Woo, K.H. Park, Structural rationale for the short branched substrate specificity of the glycogen debranching enzyme GlgX, Proteins, 78 (2010) 1847-1855.

[62] Y. Katsuya, Y. Mezaki, M. Kubota, Y. Matsuura, Three-dimensional structure of Pseudomonas isoamylase at 22 A resolution, J. Mol. Biol., 281 (1998) 885-897.

[63] L.J. Gourlay, I. Santi, A. Pezzicoli, G. Grandi, M. Soriani, M. Bolognesi, Group B Streptococcus pullulanase crystal structures in the context of a novel strategy for vaccine development, J. Bacteriol., 191 (2009) 3544-3552.

[64] B. Mikami, H. Iwamoto, D. Malle, H.-J. Yoon, E. Demirkan-Sarikaya, Y. Mezaki, Y. Katsuya, Crystal structure of pullulanase: evidence for parallel binding of oligosaccharides in the active site, J. Mol. Biol., 359 (2006) 690-707.

[65] A. East, A.E. Mechaly, G.H.M. Huysmans, C. Bernarde, D. Tello-Manigne, N. Nadeau, A.P. Pugsley, A. Buschiazzo, P.M. Alzari, P.J. Bond, O. Francetic, Structural basis of pullulanase membrane binding and secretion revealed by X-Ray crystallography, molecular dynamics and biochemical analysis, Structure, 24 (2016) 92-104.

[66] J.P. Turkenburg, A.M. Brzozowski, A. Svendsen, T.V. Borchert, G.J. Davies, K.S. Wilson, Structure of a pullulanase from Bacillus acidopullulyticus, Proteins, 76 (2009) 516-519.

[67] Y. Bai, H. Huang, K. Meng, P. Shi, P. Yang, H. Luo, C. Luo, Y. Feng, W. Zhang, B. Yao, Identification of an acidic $\alpha$-amylase from Alicyclobacillus sp A4 and assessment of its application in the starch industry, Food Chem 131 (2012) 1473-1478.

[68] M.V. Ramesh, S.M. Podkovyrov, S.E. Lowe, J.G. Zeikus, Cloning and sequencing of the Thermoanaerobacterium saccharolyticum B6A-RI apu gene and purification and 
characterization of the amylopullulanase from Escherichia coli, Appl. Environ. Microbiol., 60 (1994) 94-101.

[69] M. Nisha, T. Satyanarayana, Characterization of recombinant amylopullulanase (gtapu) and truncated amylopullulanase (gt-apuT) of the extreme thermophile Geobacillus thermoleovorans NP33 and their action in starch saccharification, Appl. Microbiol. Biotechnol., 97 (2013) 6279-6292.

[70] M. Levisson, L. Sun, S. Hendriks, P. Swinkels, T. Akveld, J.B. Bultema, A. Barendregt, R.H.H. van den Heuvel, B.W. Dijkstra, J. van der Oost, S.W.M. Kengen, Crystal structure and biochemical properties of a novel thermostable esterase containing an immunoglobulin-like domain, J. Mol. Biol., 385 (2009) 949-962. 


\section{Highlights}

- $H v \mathrm{LD}$ is 7-150-fold more active on pullulan than on $\beta$-limit dextrin and amylopectin

- N-terminal CBM-21-like domain mutants affect activity on poly- and oligosaccharides

- Phe620 and Asp621 at subsite +3 are critical for activity on branched substrates

- Phe553 at subsite +2 is important for enzymatic activity and inhibitor binding

Graphical abstract 


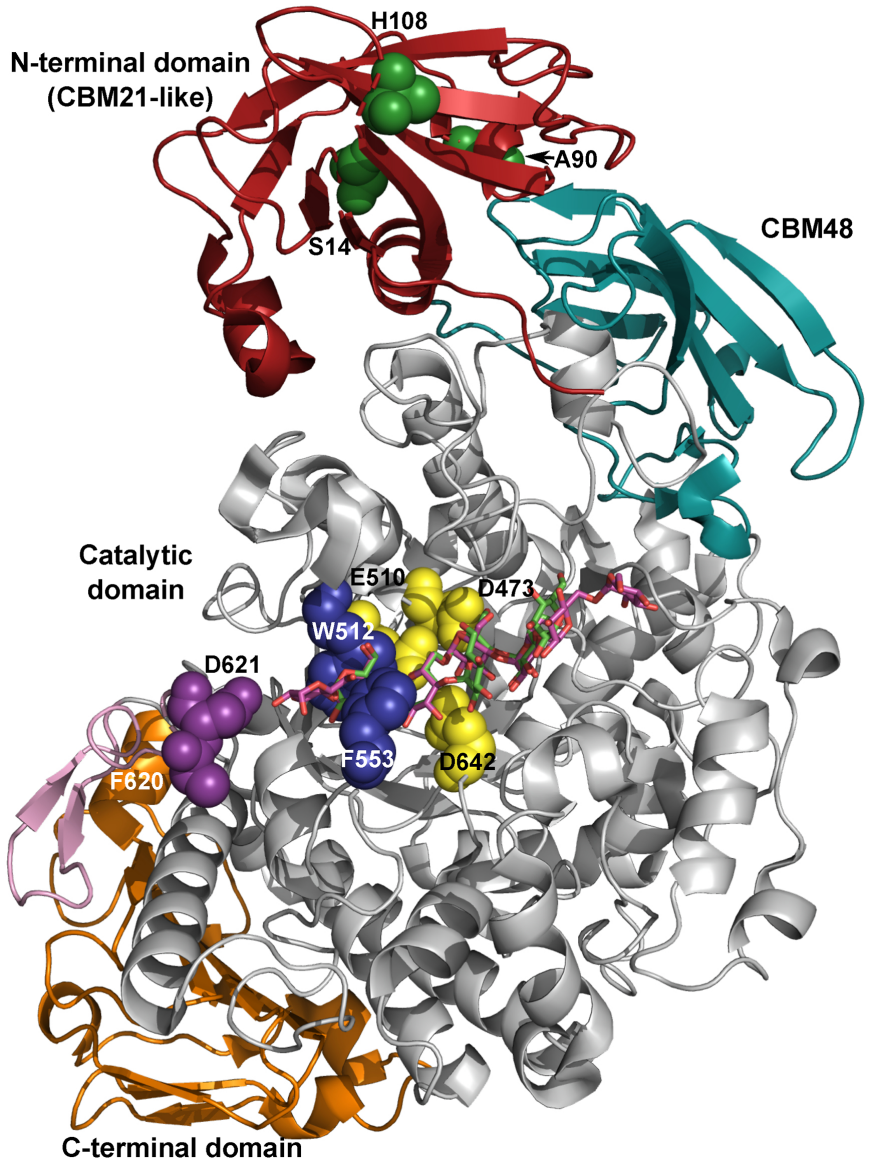

Figure 1 

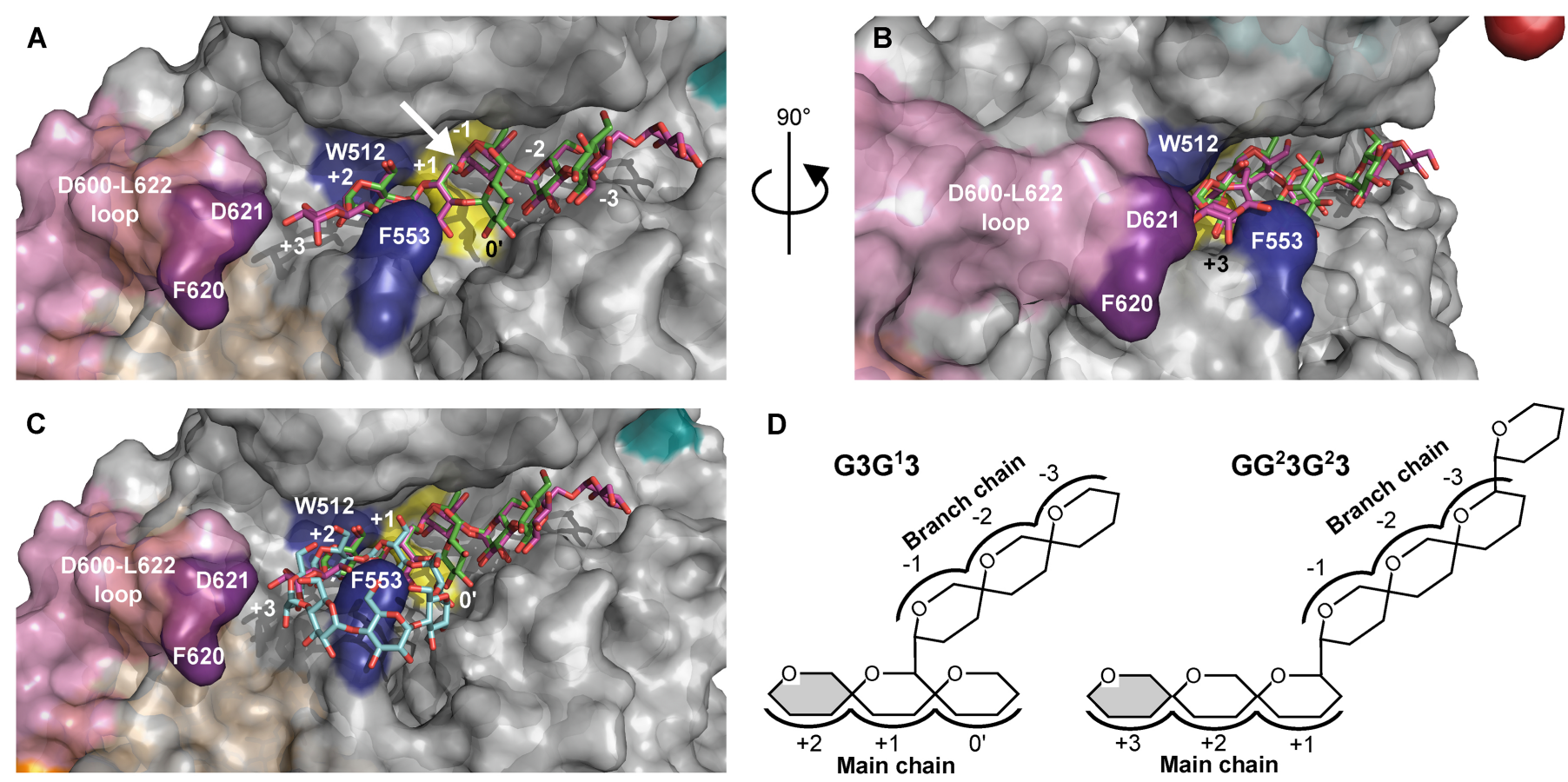

Figure 2 
1_AAF 98802 . 1 2_XP_020198569 3_ABL 84490.1 4_EMS57285.1 5 XP 003580925 6_ABK 63626.1 7 ABK 63617.1 8_XP_021318023 9_XP_008668612 10_XP_004975057 11_PAN37034.1 12_PAN37035.1 13 CAE 02111.2 14_CAC09471.2 15_ACY56102.1 16_XP_015691367 17_ONK̄57269.1 18_XP_010267259 19 OVA17964.1 20_XP_011024341 21_XP_002315334 22 GAV67655.1 23_OMO65703.1 24_XP_021295293 25 EOY18848. 1 26_KHG14018.1 27_XP_021626046 28_XP_021690509 29_XP_015876702 30 XP 010103500 31_XP_015387858 32_XP_002532780 33 XP 011469607 34_PHT29890.1 35_AOQ2 6240.1 36 CDO99808.1 37_XP_020084106 38_XP_010918919 $39 \times P \quad 008807708$ 40_XP_017409399 41_XP_007144236 42 XP 020703866

1_AAF98802.1 2_XP_020198569 3_ABL84490.1

4_EMS57285.1 5_XP_003580925 6 ABK 63626.1 7_ABK63617.1 8_XP_021318023 9 XP 008668612 10_XP_004975057 11_PAN37034.1 12 PAN37035.1 13_CAE02111.2 14_CAC09471.2 15_ACY56102.1 16_XP_015691367 17 ONK57269.1 18_XP_010267259 19_OVĀ17964.1 20_XP_011024341 21_XP_002315334 22_GAV̄67655.1 23 OM065703.1 24_XP_021295293 25_EOY 18848.1 26 KHG14018.1 27_XP_021626046 28_XP_021690509 $29 \times P \quad 015876702$ 30_XP_010103500 31_XP_015387858 $32 \times P \quad 002532780$ 33_XP_011469607 34_PHT29890.1 35 AOO2 6240.1 36_CDO99808.1 37 XP 020084106 38_XP_010918919 39_XP_008807708 40 XP 017409399 41_XP_007144236 42_XP_020703866
110

20

30

40

50

60

70

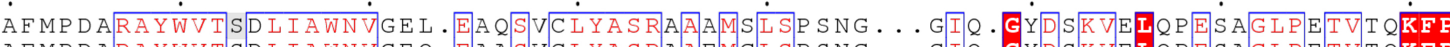

AFMPDARAYWVTSDLIAWNVGEQ. EAASVCLYASRAAEMGLSPSNG... GIQ. GYDSKVELQP ESAGLPETVT QKFP

AFMPDARAYWVTSDLIAWNVSEQ. EAASVY LYASRTA AMG L S P SNG.

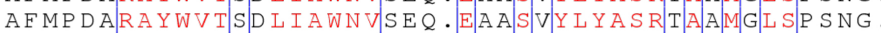

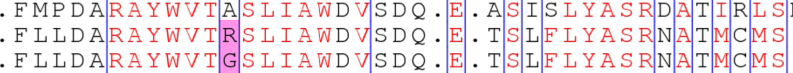

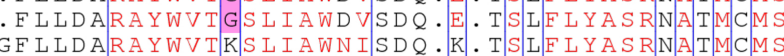

. FVSDARAYWVTSS LIAWDVISNQ.E. TSLYLYASRSATMH S

F L S DARAYWVTKS L IAWDVSDQ.E. TS L Y LYASRSA TMCM

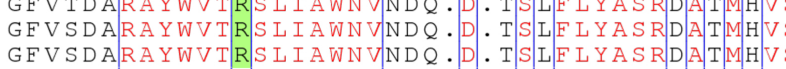

GEVSDARAYWVTRS LIAWNVINDQ. D. T S L F L YASRDATM H V
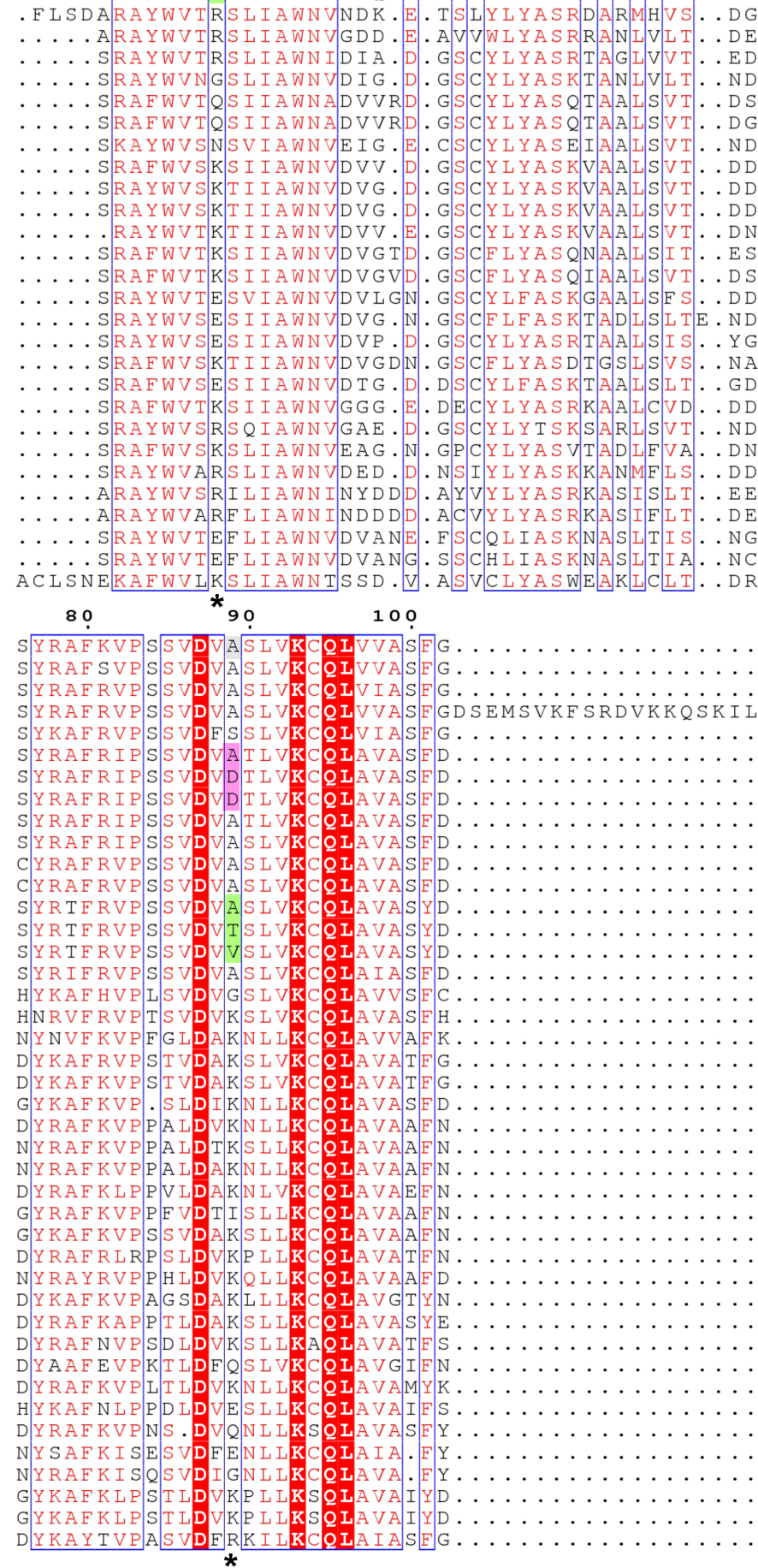

110

120

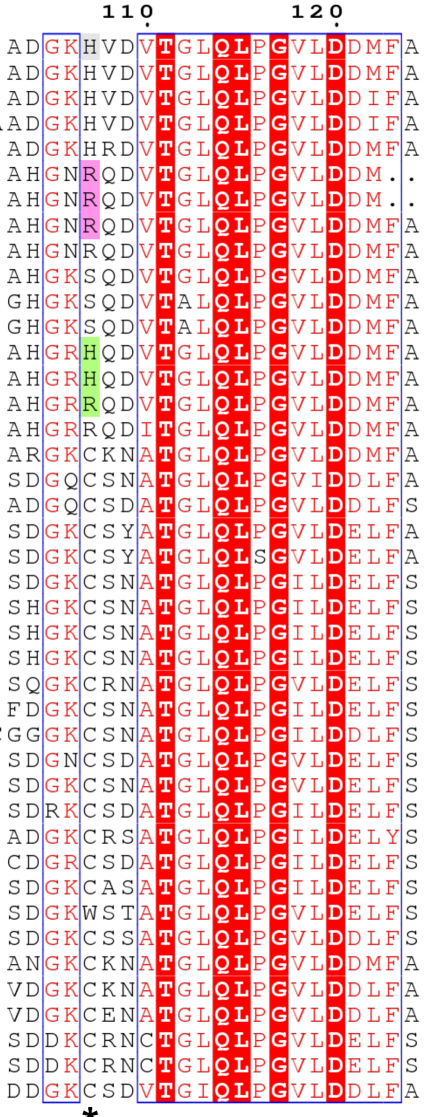




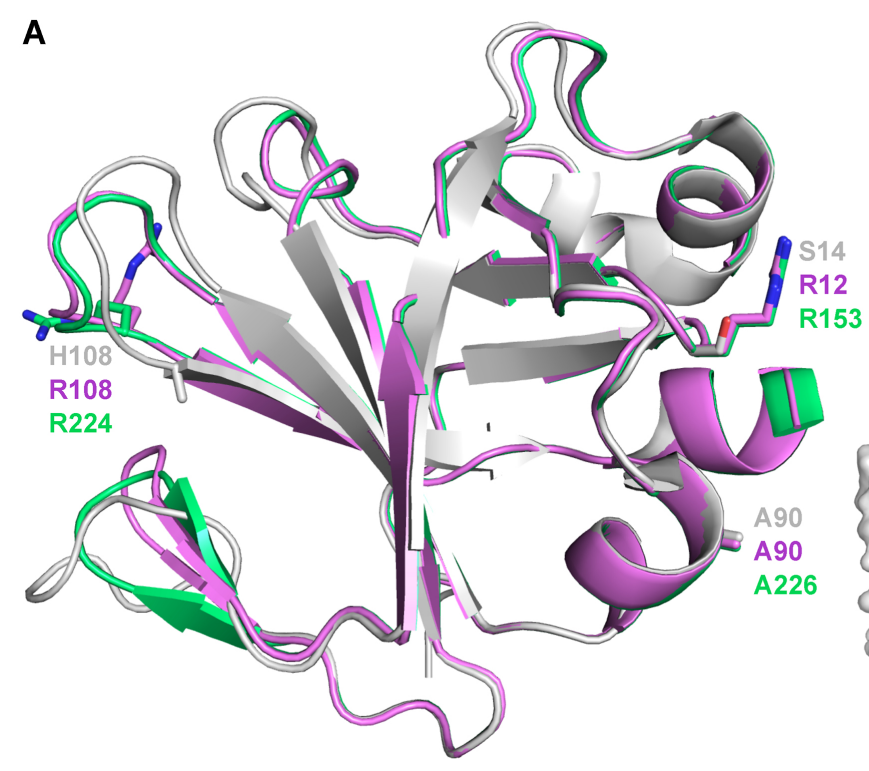

B

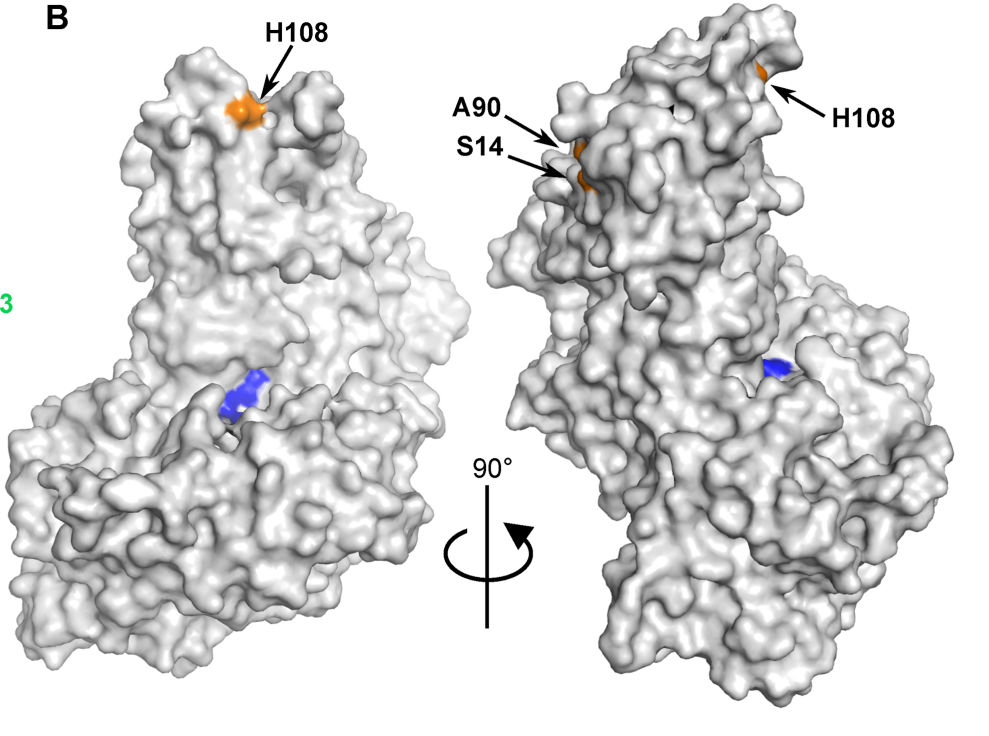

Figure 4 

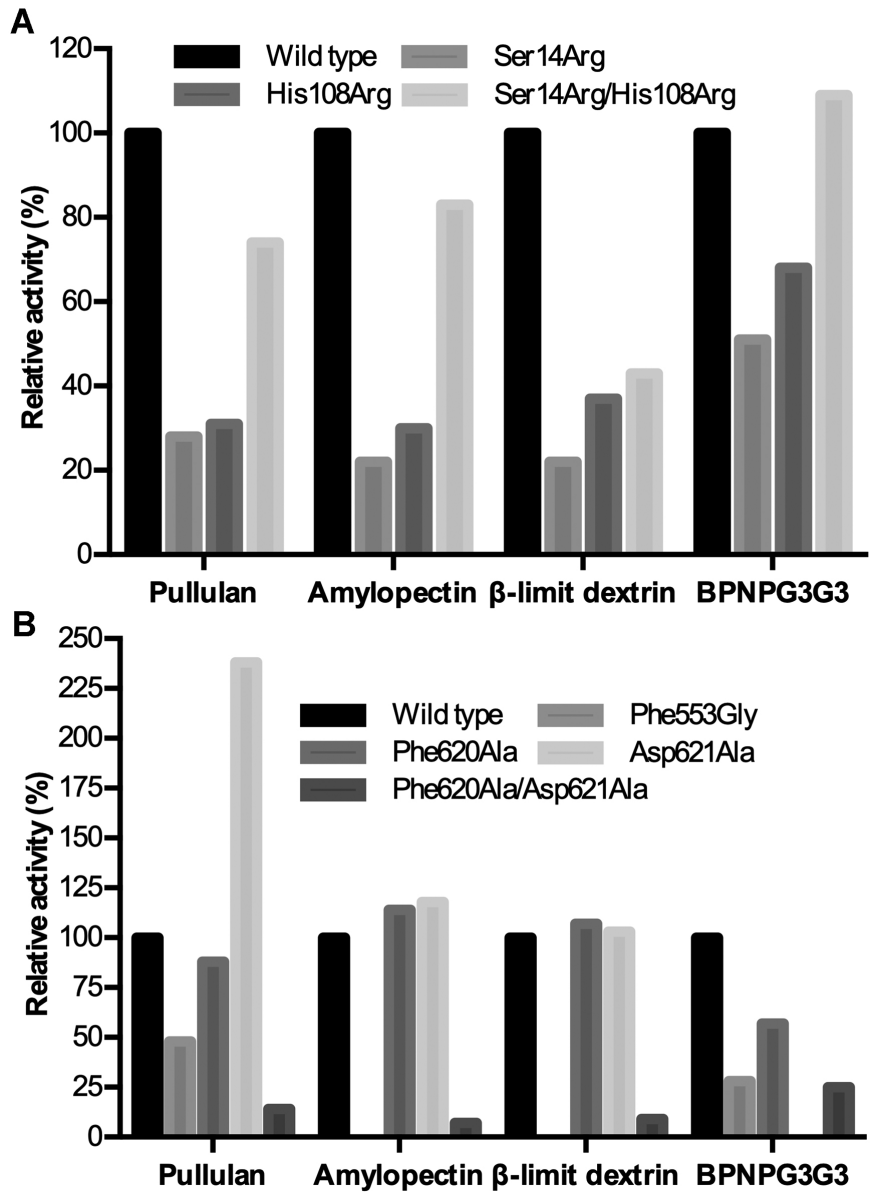

Figure 5 
GH13_39_ADZ99363 GH13 39 AAA19800 GH13_39-AFI70750 GH13_11_2vnc GH13 11 2wsk GH13 11 $1 \mathrm{bf2}$ GH13_11_4j7r GH13 12 3faw GH13_12_2ya0 GH13 13 2fgz GH13 13 2yoc GH13_13_4aio_HvLD GH13_14_3wdh GH13 14 2wan GH13_14_2e8y

GH13_39_ADZ99363 GH13_39_AAA19800 GH13 39-AFI 70750 GH13_11_2vnc GH13 11_2wsk GH13_11_1bf2 GH13_11_4j7r GH13_12_3faw GH13 12 2ya0 GH13_13_2fgz GH13_13_2yoc GH13 13 4aio HvLD GH13 14 3wdh GH13_14_2wan GH13_14_2e8y EAPMIAENWGDASLDL ........... LGDSFN SVMNYQFRNDIID .

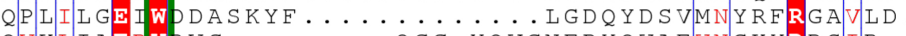
QVKIIAEPWDVG........ QGG. YQVGNFPYQWAEWNGKYRDSIR . . QVKIIAEPWDIAPG . . . . . GYQ.VGNF . PP LFAEWNDHFRDAAR . GIDIFAEPWAIGGNSYQ........LGGF . PQGWSEWNGLFRDSIRQ . NT KMIAEA WDCDG...... LNQV. GAFPHYGGRWSEWNGKFRDVVIRN . NMIMIGECWRTFQGDQGKPVKPADQDWMKS S T TVGVF SDDIRNSIKS

NIIMLGEGRTYAGDENMP TKAAD. QDWMKHTDTVAVF SDDIRNNIKS

DIYFFGEGW SNQ... SDRFEIAS. QINLK. GTGIGTF SDRLRDAVRGG

DIYFFGECWDSNQ... . SDRFEIAS. QINLK. GTGIGTF SDRLRDSVRGG K I Y I Y GE WPFAEVARNQRGINGS. QLNMS. GT G G SFNDRIRDAING G TVIILGEGDLATPL . . P SEKKTT. IANAKH TPRIAYFNDRFRDYVKG . GIVIY GEP WTGGTSGLS S D Q LVTKGQ QK. . GLG I GVFNDNIRNGID GN GILIFGE W

\section{W512}

580 590

600

610 620

$\mathbf{F 5 5 3}$

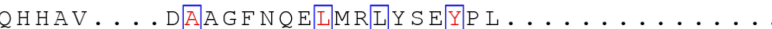
QHNP I $\ldots \ldots$ DAAK LDQR IMSIYYERYPL $\ldots \ldots \ldots \ldots \ldots \ldots$ $\ldots \ldots$ NAEEADKRITAIREDYPS ................

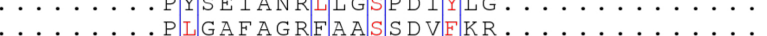
YVTODANDFSGSSNIFQS $\cdots \cdots$ P W A GDFASAICGSPNIY

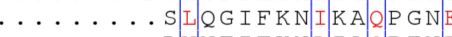
$\ldots \ldots \ldots$. . . . . . T IFKNIIAQP TNF .

SDDPR . HIADITRIG

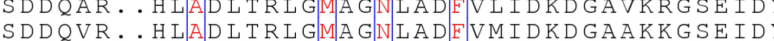
A D TRRS LA TYAD Q I Q I GIA GNLRDYVL I S T TEAKKG SE I H

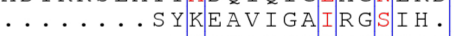

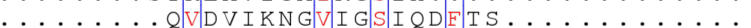
A LAP

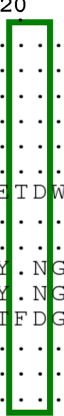
$\ldots$ FDDGNG $\ldots \ldots \mathrm{F} \mathrm{L} \mathrm{K} \mathrm{N} \mathrm{G} \ldots \ldots . \ldots$ $\ldots \ldots \mathrm{R} F \mathrm{WR} \mathrm{G} \mathrm{EAL} \ldots \ldots$

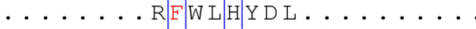
$\cdots \ldots$ A GDA LR ... NPL . QQG $\mathrm{F} / \mathrm{N} T \mathrm{G} L \mathrm{~L}$ LEP NGYQGNE

-

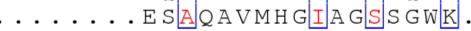

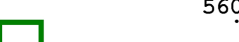

